\title{
Perceived Barriers to Persistence Related to Coping Strategies for Undergraduate Nontraditional Learners
}

Justin C. Griffith

West Virginia University

Follow this and additional works at: https://researchrepository.wvu.edu/etd

\section{Recommended Citation}

Griffith, Justin C., "Perceived Barriers to Persistence Related to Coping Strategies for Undergraduate Nontraditional Learners" (2011). Graduate Theses, Dissertations, and Problem Reports. 4724.

https://researchrepository.wvu.edu/etd/4724

This Dissertation is protected by copyright and/or related rights. It has been brought to you by the The Research Repository @ WVU with permission from the rights-holder(s). You are free to use this Dissertation in any way that is permitted by the copyright and related rights legislation that applies to your use. For other uses you must obtain permission from the rights-holder(s) directly, unless additional rights are indicated by a Creative Commons license in the record and/ or on the work itself. This Dissertation has been accepted for inclusion in WVU Graduate Theses, Dissertations, and Problem Reports collection by an authorized administrator of The Research Repository @ WVU.

For more information, please contact researchrepository@mail.wvu.edu. 
Perceived Barriers to Persistence Related to Coping Strategies for Undergraduate Nontraditional Learners

\author{
Justin C. Griffith
}

Dissertation

submitted to the College of Human Resources and Education

at

West Virginia University

in partial fulfillment of the requirements for the degree of

Doctor of Education

in

Educational Psychology

\author{
Patricia A. Haught \\ Beth A. Loy \\ Matthew M. Martin \\ R. Neal Shambaugh \\ Richard T. Walls, Committee Chair
}

\title{
Morgantown, West Virginia \\ 2011
}

Keywords: Nontraditional Student Barriers; Nontraditional Learners; Adult Learner Obstacles; Coping Strategies; Adult Learner Persistence 


\begin{abstract}
Perceived Barriers to Persistence Related to Coping Strategies for Undergraduate Nontraditional Learners

Justin C. Griffith

Nontraditional learners experience a variety of barriers to degree completion. These barriers affect graduation rates and the time it takes to graduate. The method(s) in which the adult learner deals with each barrier will determine if they persist through their program of study or fail to graduate. This study took place at a collaborative campus involving six institutions of higher learning with both a male and female population. Investigation determined, and subsequently reported, internal and external barriers to education persistence for current nontraditional undergraduate learners enrolled in a variety of majors. The investigation then determined and reported coping strategies each learner employed. Relationships between the perceived persistence barriers and the coping strategies were then measured. The results revealed that perceived barriers affected learners to different degrees. Internal barriers overall affected adult learners more than external barriers. The results also revealed both common and uncommon coping strategies. There were both strong and weak relationships between perceived persistence barriers and coping strategies, and the relationships varied across barriers.
\end{abstract}


Chapter 1: Introduction and Literature Review ............................................................. 1

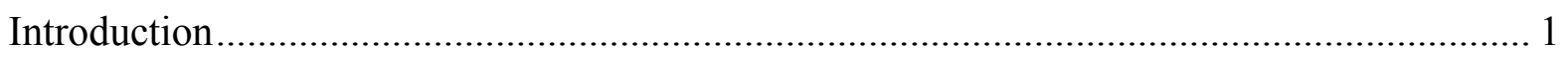

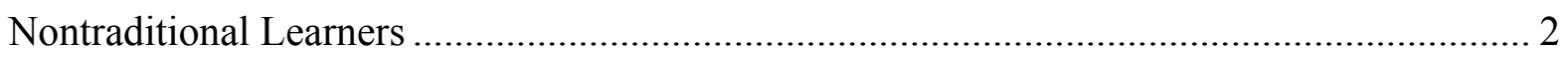

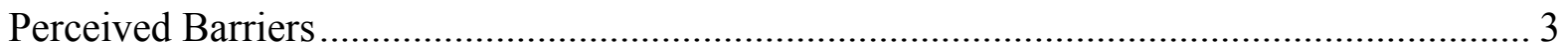

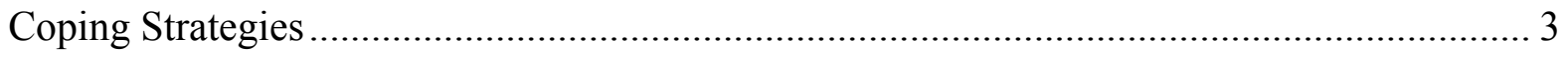

Orientation for the Nontraditional Student .................................................................. 4

Gender Research on Nontraditional Students .......................................................... 5

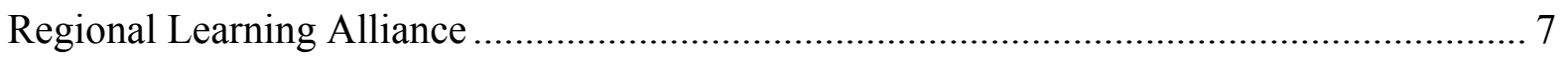

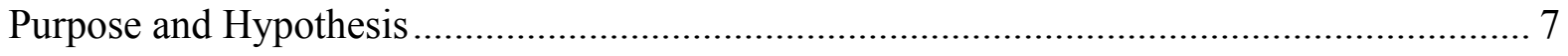

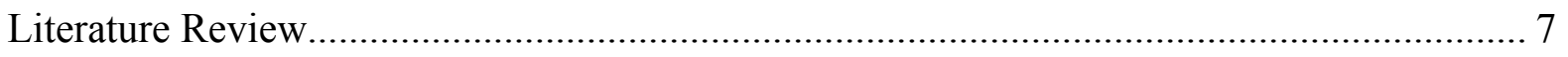

Commencement and Persistence Barriers.............................................................. 11

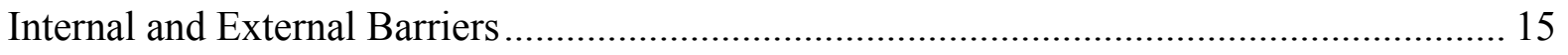

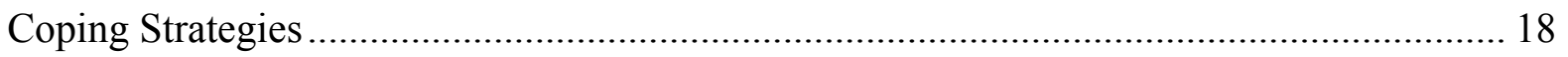

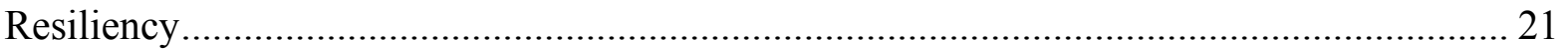

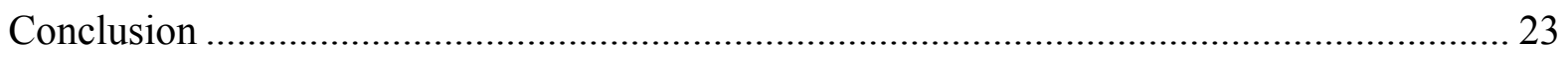

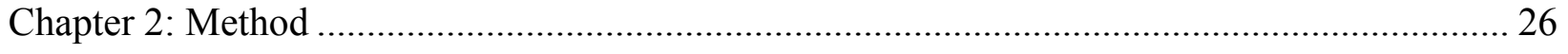

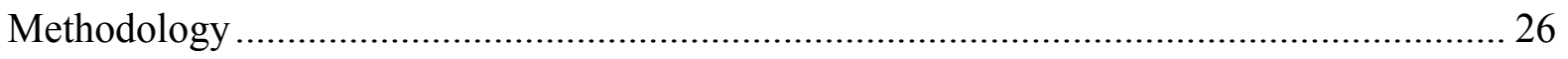

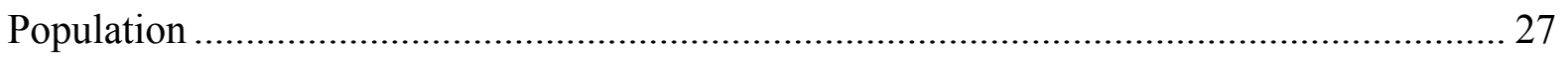

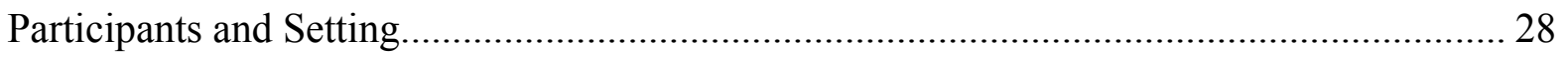

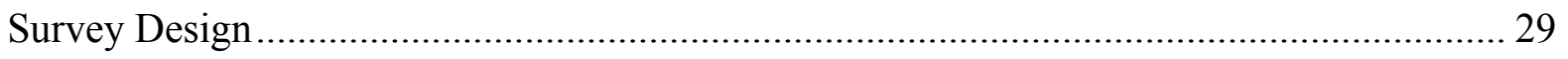

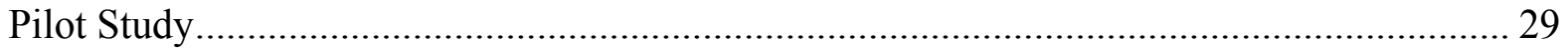




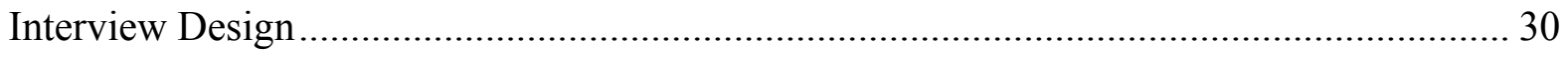

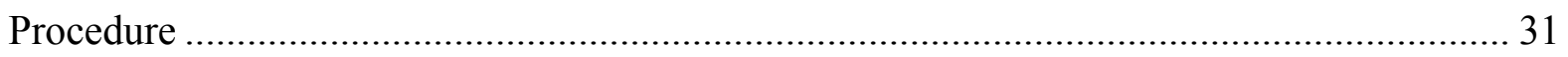

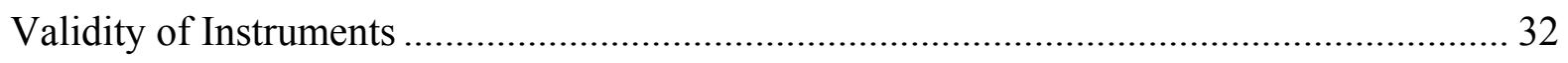

Specific Methods for Demographic Data Collection............................................................. 34

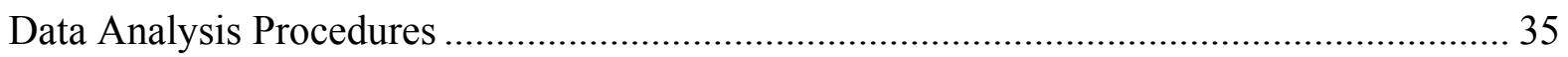

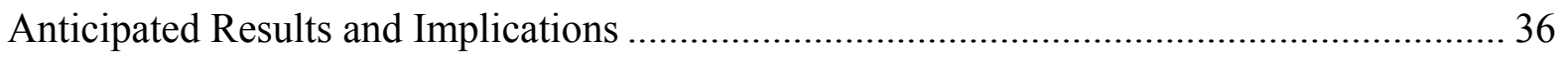

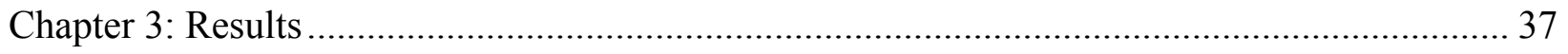

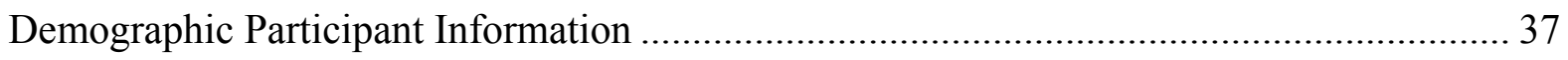

Internal Perceived Persistence Barriers ........................................................................... 43

External Perceived Persistence Barriers ................................................................................. 46

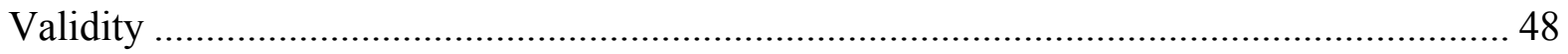

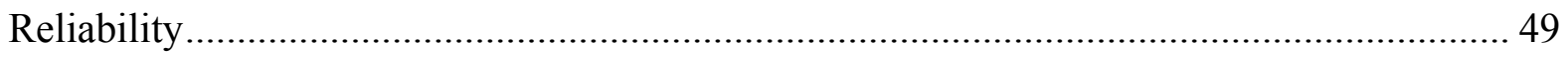

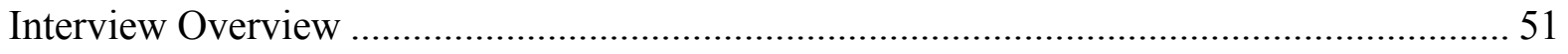

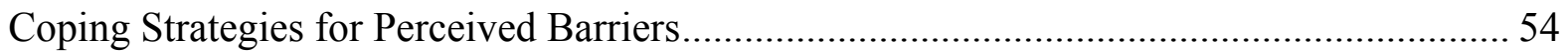

Relationships Between Perceived Barriers to Persistence and Coping Strategies.................. 60

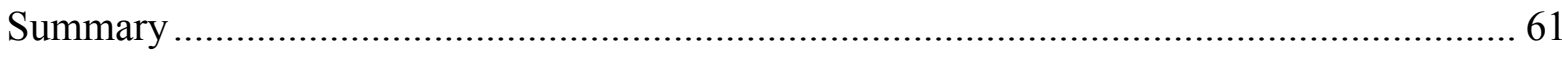

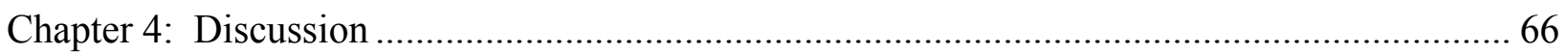

Coping Strategies Related to Internal Barriers .................................................................. 72

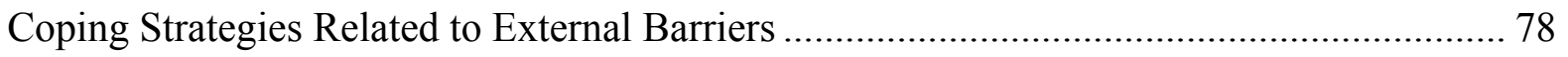

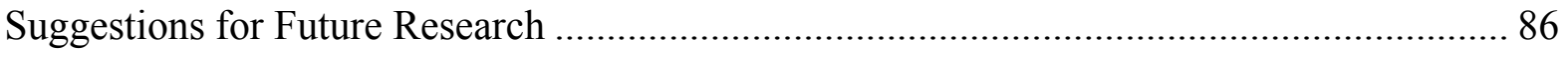

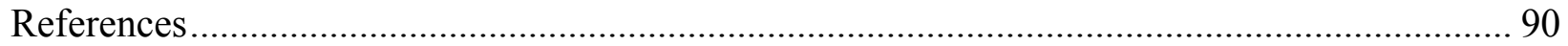

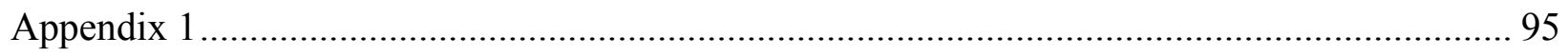

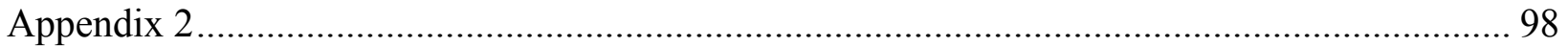




\section{CHAPTER 1}

\section{INTRODUCTION AND LITERATURE REVIEW}

"The central task of education is to implant a will and facility for learning; it should produce not learned but learning people. The truly human society is a learning society, where grandparents, parents, and children are students together."

Eric Hoffer, American Social Philosopher

\section{Introduction}

How we learn is determined by numerous factors. What we know about learning is that these factors contribute to our learning in multiple ways. Educational psychologists have recognized that the manner in which we learn is determined, in large part, by the stages of development we experience across our life span (Rutter \& Rutter, 1992). Adult learning is a stage of developmental learning that differs from that of early learning. The differences are numerous and must be studied with a distinctive approach in an effort to understand the needs, relationships, and strategies related. The barriers that adult students face differ from those of traditional students. It is a necessity for the academic environment to understand (a) these barriers faced by nontraditional students along with studying the (b) coping strategies they use to deal with barriers. Understanding barriers and coping strategies will aid in the advancement of curriculum and program development to positively assist these learners.

Adult learners have categorical differences that must be examined individually to determine how each age and step of the adult lifespan can determine learning outcomes. One feature of adult learning is that of the nontraditional learner. Nontraditional learners have been defined in various terms throughout the field of higher education. However, the most common definition of a nontraditional learner, and one that will be of concentration in this study, is - any 
learner that is age 25 or older and has not participated in a formal classroom education during a period of 5 or more years.

\section{Nontraditional Learners}

The majority of nontraditional learners tend to be part-time students. Part-time students generally attend less than 12 credit hours per semester of education. The nontraditional learner generally serves a dual role as employee along with student. A smaller percentage of learners may fit the definition of a nontraditional student but choose to go to school on a full-time basis much like that of the traditional student. It is important that these two distinctions are clarified. These factors may determine specific challenges for each learner.

Nontraditional students have become a larger percentage of the higher education population in the last 25 years. In the early 1980s, the United States population of nontraditional students totaled more than $40 \%$ of the total student population (Timarong, Temaungil, \& Sukrad, 2002). Kazis, Callahan, Davidson, McLeod, Bosworth, Choitz, and Hoops (2007) reported that in 2007 , adult students accounted for $44 \%$ of the student population. Though steady in numbers, the reasons or causes for such high percentages of nontraditional students returning to school varies.

In the early 1980 s, the return or start of formal education for nontraditional learners was primarily due to changes in job markets. Though the same reasoning still exists, the specific educational pursuits have not been consistent over that time. The bulk of educational programs initially pursued by nontraditional students were undergraduate degree programs. There have since been an increasing number of graduate programs being sought by the nontraditional student. Many of the current nontraditional graduate students were former nontraditional undergraduate students. This is valuable to note because students that have former experience as 
a nontraditional student are often better prepared to deal with their educational endeavor than are first-time nontraditional students (Wei, 2007).

\section{Perceived Barriers}

Recurrent perceived barriers exist for nontraditional students. Perceived barriers exist regardless if true barriers exist. Barriers also are realized for both commencement and persistence. Commencement barriers are those barriers that any potential student has prior to beginning a program of study. For example, funding is typically a commencement barrier that most students are faced with prior to enrollment. Persistence barriers happen after a program of study begins as students persist through their education.

\section{Coping Strategies}

There has been little research that focuses both on identifying the perceived barriers for nontraditional students and then linking those specific barriers to coping strategies. Related preceding research has simply focused on identifying barriers (or perceived barriers). Additional research has taken the barriers identified in other research studies and presented those barriers to nontraditional students in an effort to find the coping strategies applied. Though many results have provided insightful information, they have not employed a research approach that both identifies perceived barriers and then identifies the coping strategies each specific student uses to overcome the perceived barriers. The benefits of such a study could allow educators to find positive methods nontraditional learners use to cope with specific barriers and then share those positive methods with other nontraditional students. It is an opportunity to give these learners positive tools to deal with the perceived barriers they face.

Coping strategies were first identified in the field of Psychology in most published research. Coping strategies are developed and identified from infancy to adulthood as a reaction 
to others and our environment. Educational coping strategies have been studied by those interested in finding how to manage the difficulties or elements of learning. Recently a large part of that research has been in the area of autism and attention deficit disorder (ADD). Just a few studies have revealed the coping strategies utilized by the adult learner. A learner that has a barrier of time conflicts and thus uses the positive coping strategy of time budgeting is an example. That research provides strategic information for institutional planning. One missing element is the concentration on the coping strategies for students in specific educational programs.

Community colleges in particular have made it a priority to examine perceived barriers and coping strategies in an effort to assist nontraditional students. Community colleges typically have a higher-than-average proportion of nontraditional learners. However, a multitude of higher education institutions still have not come to realize that nontraditional students should be recognized as a separate student population having specific needs and learning perspectives. Many institutions address their nontraditional students via a lifelong learning or continuing education division. These divisions specifically focus on the adult learner with attentiveness to the nontraditional student. They not only provide learning resources, but often dedicate programming to this student population. Nontraditional learners often find degree programs offering a customized structure most conducive to their learning, including evening and weekend classes, cohorts, and credit for professional experience. Even so, there seems to be one relevant missing link from the critical majority of these programs. That missing link entails the orientation process for students as they start their new educational journeys (Donaldson \& Townsend, 2007).

Orientation for the Nontraditional Student 
Unique barriers do exist for nontraditional students according to widespread research. These barriers vary according to (a) the type of program in which the student is enrolled (Price, 1998) and in (b) the level of learning, (c) gender of the student, and (d) status of each student. Traditional students, at many educational institutions, are required to receive an orientation to the university. Often this is delivered in the form of a one-day orientation and/or one-credit hour semester-long "Introduction to the University" class. This type of class often teaches students about university resources, situations that may defray student progression, risk to academic performance, social skills, balancing school and social commitments, and a host of other topics. These classes are seemingly effective for traditional students and have been implemented nationwide. The concept is virtually nonexistent for the nontraditional student. In fact, most nontraditional students do not receive any type of orientation upon their start or return to higher education (Donaldson \& Townsend, 2007).

Nontraditional students could benefit greatly from an orientation program that underscores their specific needs. There is currently a gap in the published literature specifically on the reasoning, structure, and content of such an orientation program. Further research may be recommended, focusing on the elements necessary for an orientation program or class offering during the beginning of a nontraditional student's educational undertaking. This research may be of considerable aid to the nontraditional student, resulting in greater percentages of matriculation, participation, and persistence through academic programs.

\section{Gender Research on Nontraditional Students}

The majority of nontraditional students, since the early 1980's, has been female (Timarong, Temaungil, \& Sukrad, 2002). This research, often conducted in the Women's Studies field, has studied the reasoning for gender differences in a variety of educational programs for 
nontraditional students. One substantial point for consideration is the previous gap in the percentages of males and females enrolled as traditional students. In the 1970's, the majority of traditional students were male. Subsequent research pointing to female statistical gains in traditional education programs then prompted enrollment research indicating larger gains for women as nontraditional students.

Gender-specific enrollment differences in nontraditional programs do exist according to at least one major study (Timarong, Temaungil, \& Sukrad, 2002). Knowing this, it is important to recognize that recent trends suggest shrinkage in the percentage gap between males and females in adult education programs. With these national changes now becoming more inclusive of males as nontraditional students, there is expected to be further gender inclusive studies taking the place of past female-exclusive programs.

Gender studies, related to nontraditional students, detail a common female role as primary family caregiver and compare that role to male counterparts. This known, the research has indicated females often rank "role conflict" as a major barrier (Satterlee, 2002). This relating role conflict has generated additional studies underlining conflict resolution strategies between the roles of family member, spouse, mother, student, and employee (Satterlee, 2002).

Nontraditional students make up a sizeable portion of the formal student population, and yet orientation programs for nontraditional students are diminutive. Hence, additional research is needed to gain the necessary information to develop orientation programs that better serve these students. Research should focus on identifying specific gender-neutral barriers for nontraditional students in a variety of undergraduate programs. Additionally, there should be a focus on the identification of coping strategies and the relationship of those strategies to these gender-neutral barriers. 


\section{Regional Learning Alliance}

The Regional Learning Alliance (RLA) is the nation's largest collaborative campus located in Cranberry Township, Pennsylvania. Twelve universities share one technology-based campus. These universities operate regional branch campuses from the RLA campus and most offer complete degree programs. Slippery Rock University of Pennsylvania created the campus and has a contract with the Alliance for ongoing management. The Regional Learning Alliance was formed as a separate 501(c)3 educational entity with a 12 member Board of Directors that steer the mission and vision. Slippery Rock University is located in Slippery Rock, Pennsylvania and is one of fourteen state universities operated by the commonwealth. The additional universities include ten private institutions along with West Virginia University. These institutions combined offer 38 degree programs and in a wide variety of curricula, both undergraduate and graduate levels at the Regional Learning Alliance campus. The campus has been in operation since 2004, has 28 classroom and computer labs in a variety of sizes that include a great hall and an auditorium. The campus additionally houses a full-service training and conference center serving 700 corporations and organizations in the commonwealth, nearly 40,000 people yearly, with non-credit professional development.

\section{Purpose and Hypothesis}

The purpose of this dissertation is to identify the perceived barriers to persistence and the coping strategies for nontraditional learners enrolled in a variety of adult undergraduate programs at the Regional Learning Alliance. Further investigation explores the extent to which relationships exist between the perceived barriers to persistence and coping strategies. The research questions posed in this study include the following. RQ 1) What are the perceived barriers to persistence for nontraditional learners enrolled in a variety of adult undergraduate 
programs? RQ 2) What are the coping strategies related to the perceived barriers for nontraditional learners enrolled in a variety of adult undergraduate programs? RQ 3) Do relationships exist between perceived barriers to persistence and coping strategies for nontraditional learners enrolled in a variety of adult undergraduate programs and, if they do exist, to what extent? The hypothesis is that (a) relationships will exist between various perceived barriers for nontraditional students and coping strategies and (b) the extent to which relationships exist between perceived barriers and coping strategies will vary across barriers. This study should offer further understanding of nontraditional student need and aid in the development and revision of a variety of educational programs provided to nontraditional students.

\section{Literature Review}

The literature review has taken form by the statements and purpose put forth from the introduction. The approach is to further explain the research that exists which details nontraditional learners, the perceived barriers to commencement and persistence through an educational program they may have, and the resulting coping strategies they use to deal with those perceived barriers. This section serves to explain why it was necessary to conduct this study and how the existing literature and research supports or does not support the hypothesis put forth. To understand perceived barriers nontraditional learners may have, it is necessary to more thoroughly understand the dominant known characteristics of adult learners.

Eduard Lindeman marked the beginning of adult education as a field in 1926 with his book The Meaning of Adult Education. The term "andragogy" was later embraced by Malcolm Knowles who has perhaps contributed the most specific philosophy to the field of adult education. Knowles defined andragogy as "the art and science of helping adults learn" 
(Knowles, 1984, p. 43). Understanding Knowles' basic assumptions about adult learning helps one to relate to the adult learner and ultimately understand them better.

Knowles' model of andragogy incorporates six basic assumptions. The first assumption is that adult learners need to know why they need to learn. They will invest energy into learning if they know the negative consequences of not learning it. The second assumption is that adults have a self-concept of being responsible for their own decisions. They go from being dependent personalities to being self-directed. Adult learners transform from teacher-dependent to learners that direct their own learning. Third, adults come to education with a different quality of experience than do children and adolescents. This assumes that adults have more experience to relate to the material being taught than do younger learners. Fourth, adults become ready to learn those things they need to know to cope with real-life situations. The timing of learning is related to development tasks. In other words, adult learners are more interested in what is relevant and of interest to them. The fifth assumption from Knowles is that adult learning is problem-centered rather than subject-centered. Adults wish to learn something that can solve a problem and are more apt to get bored than children learning subject-centered material. Finally, the sixth assumption is that adults are internally rather than externally motivated.

Focus of my theoretical analysis is not a comparison of andragogy and pedagogy (the art and science of teaching children) but rather understanding that adult learner needs are unique and specific and change as we age. Traditional-age college students (17-24) may require a different orientation to learning than that of the adult student that I will herein refer to as "nontraditional learners." Understanding nontraditional learner basic assumptions is a necessary element needed to discuss unique adult learner needs. 
The standard definition of a nontraditional undergraduate learner has been developed over the past 35 years and is categorized as individuals age 25 or older who have been out of a formal learning environment for five or more years (Schuetze \& Slowey, 2002). Many higher education institutions today have added elements to this standard definition, often listing "employed at least part-time" and "living independently" or "not at home." Marion Bowl (2001) says that nontraditional learners differ from traditional learners when it comes to multiple role commitments. Nontraditional learners often have roles of employee, spouse, parent, and family caregiver, which differ from that of a traditional learner. According to Ellen Fairchild (2003), a majority of nontraditional learners are employed full-time in careers. This presents them barriers that go beyond that of traditional-age students.

To understand perceived barriers nontraditional learners may have, it is necessary to understand the dominant known characteristics of nontraditional learners. Timarong, Temaungil, and Sukrad (2002) have said that the majority of nontraditional learners are and have been female. Gender differences have been recognized since the term "nontraditional learner" was coined. A large and diverse body of research on gender differences has been conducted for more than 35 years to explain why a much larger portion of women pursue educational endeavors as nontraditional students than do males (Justice \& Dornan, 2001; Leppel, 2002). In 2003, college students ages $18-24$ were $45.9 \%$ male and $54.1 \%$ female, according to statistics from the Colleges and Universities Education Digest (2005). Additionally, $61.9 \%$ of students ages 25 and older were female. This disparity has remained approximately the same for more than 30 consecutive years. Females are the majority of the student population both traditionally but even more so nontraditionally. Consequently, most literature on nontraditional learners and perceived barriers focuses predominantly on the female population. 
Investigation of nontraditional students includes obtaining the reasoning behind their choice to become a student. Benshoff and Lewis (1992) reported that most individuals state work-related issues as the largest rationalization for their becoming degree-seeking nontraditional learners. This divides into two main reasons, to change a career field and to advance in a current career. Advancing in a current career is more widespread than changing career fields for both males and females (Benshoff \& Lewis, 1992). Changing career fields is more common in the female population than in the male population (Benshoff \& Lewis, 1992). It is important to note that a more recent study has reported this similar finding. There are only a

few research studies, e.g. Bowl, Chartrand, Kemp, with designs that do not differentiate male and female nontraditional students as their population. Study involving both gender inclusions for nontraditional students related to their perceived barriers is necessary. The necessity comes from the need to understand all perceived barriers and related coping strategies from both a female and male perspective and therefore will be studied without disaggregating data by gender.

\section{Commencement and Persistence Barriers}

Barriers to commencement to enrollment for nontraditional students are vastly different from traditional learners. Enrollment for traditional learners is more expected than enrollment for nontraditional learners. Nontraditional commencement is not a natural educational progression in life. Typically, it is an extraordinary experience for them to commence into an educational program while they have other full-time commitments such as career, along with roles within a family unit. Another factor according to Keith (2007) is that nontraditional learners often feel inadequate and unprepared to become a student. Therefore, they often do not enroll because of real or perceived barriers. 
A consistently popular reason for entering a program of study for nontraditional students is self-development/self-esteem. A study by James (2003) reported results that self-esteem, or more importantly building self-esteem, is the second most likely reason behind "work-related" that nontraditional learners enter a program of study. Self-development is woven into self-esteem in most studies. In other words, if you enter a program of study for self-esteem reasons, then you are most likely also working on your self-development. Self-development includes wanting to "fit in" with others both socially and professionally. Fitting in and the feelings associated with that, do build both an individual's self-development and self-esteem as nontraditional learners according to James (2003).

If students have tools to deal with perceived barriers, they will be more likely to overcome these barriers in a successful way (Timarong, Temaungil, \& Sukrad, 2002). Throughout this theoretical analysis, reference has been made to perceived barriers rather than real barriers. Research has said that often barriers are not real but rather perceived (McWhirter, 1997). Perceived barriers may exist in the mind of the individual but may not exist in reality. An example could be deficient time for a student to complete the necessary assignments for class. This perceived barrier could possibly be eliminated if she were to manage her time in a different way that allows her to complete the tasks or, possibly she could learn study skills that will give her ideas to decrease the time it takes for her to complete an assignment. A possible perceived barrier to commencement to an educational program may be financial deficiencies. The individual may have other ways to fund her educational journey and thus remove that perceived barrier.

Past studies including those by Timarong, Temaungil, \& Sukrad (2002) and James (2003) have given the following barriers listed by the sample of the population in their respective 
studies: not sufficient time, role conflicts, lack of preparedness, lack of knowledge, lack of child care, employer demands, lack of funds, lack of concentration skills, feelings of insecurity, feelings of not fitting in with others, low self-esteem, entrance requirements, and lack of family support, among others. These barriers have been identified through these studies but may or may not be the only perceived barriers that exist for nontraditional learners. Additionally, these barriers are not distinct as either barriers to commencement or barriers to persistence. These barriers are, however, specific to nontraditional learners. In a study of traditional learners, perceived barriers differ drastically between nontraditional and traditional learners (Donaldson \& Townsend, 2007).

Various methods in various studies have identified perceived barriers. The study by Timarong, Temaungil, and Sukrad (2002) consisted of a questionnaire with a list of barriers already conceived. This questionnaire allowed participants to choose from a list of barriers and put them in rank order. It did not allow participants to list any other unique individual barriers that existed. Therefore, participants may have had barriers that they could not list because there was no such option incorporated within the questionnaire design.

A study by Fairchild (2003) utilized past research to list multiple choice barriers in a participant survey and then went further to allow participants to list other barriers they had that were not listed in the multiple choice options. This mixed methods approach gave a more realistic picture of the types of barriers that existed. The study did not make any distinctions between perceived commencement barriers and perceived persistence barriers. Not making this substantial distinction is important to note as participants in the study were already enrolled in an undergraduate program and thus have obviously overcome any commencement barriers they may have been presented prior to enrollment. Any barrier with less than $5 \%$ response was left off 
of the results, which did not allow a comprehensive list of barriers to be considered. In addition, this study was completed by all female participants. Had male participants existed in a percentage reflective of the total population of nontraditional learners nationwide, a much different response rate for barriers could have resulted. Child care for example, may be much lower on the list of perceived barriers for male learners. No other research has been found that addresses a design that (a) considers both genders, (b) separates barriers to commencement from barriers to persistence, (c) allows participants to list any barriers unique to them (rather than exclusively multiple choice options) and (d) makes clear distinctions between internal barriers and external barriers. These four design variables will be included in a survey and interview sequence for the present investigation.

Nontraditional learners enrolled in programs of study often find difficulty as they persist through their educational journeys. Persistence through an educational program is often the most difficult aspect of being a nontraditional student (Satterlee, 2002). Once a student overcomes the barriers through the commencement or enrollment process and returns to school, they then face additional perceived retention or persistence barriers that may cause them to cease continuation. In 2003, King reported that approximately $37 \%$ of nontraditional learners that enrolled in a program of study would persist through their program of study to graduation with a four-year degree. In comparing these rates over the last 20 years, we see only slight changes in the graduation rates for nontraditional students. This suggests that more needs to be done to change these percentages to result in more students persisting through their programs to completion.

One recent report by Spellman (2007) detailed both enrollment and retention barriers for nontraditional students. This was not a research study but rather a report on the state of adult students and a recognition of barriers found through experience and other research studies that 
have recently been conducted. This report was created in an effort to share the importance of a community college focusing on the recognized barriers to obtain adult student enrollments and increase retention rates. Spellman contended that barriers which prohibit an adult student to commencement should be divided into situational, institutional, or dispositional. She then divided retention (persistence) barriers into social, academic, and institutional. These categories of barriers were described in detail with thorough explanation of cause and effect for each barrier. Though this is considered a report rather than a research study, it is one of the more thorough and detailed of any nontraditional learner report found. This report (Spellman, 2007) can be a model for designing a more comprehensive barriers survey for study.

This study focused on persistence barriers. Participants in this study were enrolled in an undergraduate program and had thus overcome any commencement barriers in order to begin their program(s). Thus, study of commencement barriers could be designed such that participants were potential students that have applied to an undergraduate program or college but have not become enrolled. This study was found necessary and should lead to further investigation beyond this dissertation. Orientation programs specifically address persistence barriers. However, recruitment, admissions, and financial aid departments may find it important to have information regarding any commencement barriers of nontraditional students. They can utilize such research results to design and adjust admission programs, financial aid packages, and programs that assure students they will be addressing specific barriers prior to enrollment. This could potentially allow institutions to increase their enrollment of nontraditional students as well as allow nontraditional students to enter a program with a feeling that the institution has offered substantial support to their needs.

Internal and External Barriers 
Internal barriers related to nontraditional learner persistence are psychological challenges one may face when enrolled in a program of study. External barriers related to nontraditional learner persistence are challenges presented by an individual's environment. According to Stern and Oskamp (1987), environmentally substantial behaviors are the outcome of both internal and external factors. Internal factors are unique to an individual and include personal attitudes, beliefs and knowledge, while external factors are more macro-level forces that are typically outside of an individual's control (Connell, 2010). According to Connell (2010), examples of external forces influencing environmentally substantial behaviors include social institutions, economic forces, and physical structures. According to Stern and Oskamp (1987), proenvironmental behaviors are the result of both personal attitudes and values, and external conditions. Furthermore, external conditions act as either sources of support for or opposition against differing behaviors (Connell, 2010).

Some obstacles to student retention are beyond the power of the college to overcome, but research and experience have shown that identifying both internal and external obstacles for targeted group of students can lead to effective strategies that focus on the specific needs of that targeted group (Noel, 1985). Resiliency studies have been progressively recognizing the importance of separately identifying internal and external barriers an individual may have in an effort to research how they each play a part in decision-making and emotional intelligence. In a resiliency study by Hsu and Tung (2010) on the effects of internal and external resources to adaptation and psychological well-being, they recognize a gap in research comparing the effects of internal and external barriers. The study purpose was to verify the complex mechanism of multiple resources through which psychological well-being is reached in an effort to establish whether it is internal or external resources that have the larger effect on psychological well-being 
and adaptation. Barriers faced by nontraditional students include both internal and external barriers. Distinguishing between internal barriers and external barriers will aid in the understanding of barriers and will help in the methods used by colleges to help nontraditional students with all barriers.

Anxiety and worry are prevalent internal barriers for both traditional and nontraditional students according to a study by Price (1998). This study examined differences in traditional and nontraditional students that included the anxiety levels in each using the General Anxiety Scale by Sarason \& Ganzer (1962). In this test, there were no real differences in the levels of anxiety associated between traditional (under age 25) and nontraditional (over age 25) students. However, the levels of anxiety were high in both. A study by Nicholson and Bess (1997) explored anxiety specific to the adult student and concluded that it is valuable for faculty and administrators of higher education programs to know the anxiety felt by each student at the time of program commencement so that appropriate support and teaching methods can be employed. Their example included highly anxious students not being a good fit for independent and unstructured courses. It was reported that high levels of anxiety in their nontraditional student participants may well justify consideration of customized policies (Nicholson \& Bess, 1997). Both related studies impressed the importance of recognition of anxiety as a substantial reason why adult students do not persist through their undergraduate programs and thus orientation programs, tailored advisement, and other programs were suggested to curb drop-out rates in this population.

Mercer (1993) identified two types of external barriers for adult students, situational and institutional. Situational barriers include roles in a family, employment, and civic duties while institutional barriers included tuition expenses and inconvenient class times. Keith (2007), 
studied 138 nontraditional students ages 25 to 63 with a focus on the support services involving the institutional-related external barriers and the multiple role external barriers such as student, spouse, parent, employee, and civic volunteer. The findings pointed to some interesting aspects of external barriers. Students employed full-time used less institutional services for help, but tuition increases had a direct effect on the usage of institutional services. In other words, when tuition increased, so did the stress level of nontraditional students and their use of services such as the financial aid office. Nontraditional students with characteristics closest to traditional students did use more student services from the institution. Therefore, one can conclude that the more roles that an adult student takes on, the less likely they will be to engage the institution services. This could be due to an insufficient amount of time to utilize these services.

\section{Coping Strategies}

A purpose of finding perceived barriers is to then assess how participants cope with the barriers to overcome or deal with them. Satterlee (2002) revealed that conflict resolution is a major mechanism or coping strategy for dealing with multiple barriers for the nontraditional learner. She reported that nontraditional learners have conflict between their various roles, whether it be as employee, spouse, parent, or other. When conflict arises, the student deals with it in various ways (Satterlee, 2002). The strategy they use to deal with these conflicts, or learning how to resolve them, are coping strategies.

Study by Elsa Price (1998) determined and examined the coping strategies used by nontraditional students. The study focused primarily on asking participants to identify how they cope with a set of given barriers such as time constraints or family commitments. The study only incorporated given barriers, thus not allowing participants to identify any barriers not supplied on 
the survey. The study then related the barriers selected by participants to coping strategies that are also supplied to participants on the survey.

One study by Green, Bird, and Piercy (2008) used a pre-supplied set of given barriers and also included a method that allowed students to reply to a statement, "Choose from the following coping strategies to explain how you deal with school-related stressors." Again, participants were asked to choose from a series of options (coping strategies) rather than list any responses. This may have inhibited responses potentially obtained if the barrier options and the coping strategy options were not pre-selected.

This investigator found no known studies that allow nontraditional learners to (a) list barriers unique to them (in addition to a multiple choice option), and (b) then allow nontraditional learners to identify any directly related coping strategies. A more open-ended design allows participants to give any number of responses and thus a more thorough mechanism for results. This reduces the bias other studies have displayed in their methodology. Using an open-ended strategy thus made this study more qualitative in nature. This study was designed with an all-encompassing understanding of the relationships that exist for nontraditional students between their perceived barriers to commencement and persistence and resulting coping strategies.

Spellman (2007) reported that (perceived) barriers that have been stated universally include financial, family commitments, and cultural barriers such as language. Another consistent barrier is lack of child care for those nontraditional students with children (Bowl, 2001). These reported barriers have been incorporated on other related surveys as a set of multiple choice options for participants to select from (Kemp, 2002). Studies that have given heed to more open-ended questions of its participants have been fewer. Because many barriers 
are considered universal, studies tend to list these barriers as options participants choose from when identifying the barriers they may have. If participants experience any barrier(s) that are not listed as an option, the barrier(s) does not get reported. Allowing participants to express their thoughts about perceived barriers and coping strategies on an open level, may encourage more information about their status as a nontraditional student to be revealed. Such an open design thus requires participant responses to be categorized, given that participants may intend to report the same barrier by definition but report it in different ways and with different language.

Support systems factor into whether or not the student may use coping strategies effectively (Bowl, 2001). Support systems are a key concept in dealing with stress and problems brought on by the role of nontraditional students. Chartrand (1992) identified social support systems as critical predictors of psychological adjustment (coping strategies) for nontraditional students. Other support systems, both family and institutional are also key elements of how an individual copes with the barriers they are faced with as an adult student. Simply put, coping strategies may be the tools that are developed by institutions, family and friends of the student, and peers of the student in an effort to support that student. If an adult student has, for example, a peer that is willing to study with them, that is considered a social support system necessary for the student to cope with the demand of the program of study or other barriers such as a lack of study skills. Since different kinds of coping strategies would bring about different effects and impacts to adaptation and psychological wellbeing, Hsu and Tung (2010) hypothesized that positive coping strategies have a positive relationship to adaptation, whereas negative coping strategies show a negative relationship to adaptation. In addition, positive coping strategies are related to less depressive symptoms and higher life satisfaction, while the negative coping would be related to more depressive symptoms and less life satisfaction (Hsu \& Tung, 2010). 
Educational institutions need to adapt to the nontraditional student (Bowl, 2001).

Assistance obtained from educational institutions can either help the learner to succeed in his/her program of study, or the lack of coping strategies can result in failure. Programs designed to give nontraditional students the tools they need to succeed are listed as a priority for nontraditional students (Bowl, 2001). Not only could these tools be a mechanism to help learners cope with their programs, they could provide schools with the opportunity to increase their retention rates. The goal of most studies related to barriers and coping strategies is for institutions to learn information about adult students in an effort to help them to persist through successful completion of their program of study. Beyond this study, further research could be completed to find nontraditional student assistance to overcome barriers from their educational institution. That study may reveal links to student perceived barriers to both commencement and persistence and may affect other coping strategies they develop and use. The present investigation was designed to reveal barriers and coping strategies that normally would not be disclosed in studies that have predefined choices for each of these topics.

\section{Resiliency}

It is said that students who do well and/or succeed in an educational program have resilience to overcome perceived barriers. Resilience is a field of study related to psychology. Resiliency has been used to describe an individual's ability to cope with adversity and/or stress in effective ways that may result in increased ability to respond to future adversity (Kemp, 2002). Resilience is the effective outcome of successful coping strategies. Since a good deal of literature exists on the topic of resiliency related to students, it is certainly relevant to review literature specifically involving adult student resiliency. 
Kemp (2002) designed a research study that investigated persistence, life events, external commitments, and the resulting relationships in adult undergraduate male and female students. This study discussed persistence as including protective factors which are skills, environmental supports, and personality factors that contribute to resiliency. This is important to note because other research regarding adult student persistence through a program of study does not mention that there are protective factors that help them cope with any barriers they face. Kemp notes that protective factors provide a buffer and reservoir of resources to deal effectively with the stress involved with persistence. We can thus conclude that the more protective factors (and the stronger the protective factors) the adult student can deploy, the more apt that student will be to deal with and overcome barriers (e.g., stress). Consequently, the student will be more apt to persist through their educational program if they have strong protective factors.

A study related to the adult distance education student by Kemp (2002) included two resiliency tests and a questionnaire which were more open-ended, allowing for self-reporting by participants. An element of self-reporting in such a study appears necessary in order to obtain more thorough results. There were several limitations to the Kemp (2002) study, including no clear definition of what he defined as an adult student, and the author's clear caution that the study does not have generalizability. The study included participants from one college with characteristics unique to the region, and thus, Kemp stated that the study results could not be generalized to the national population of adult distance education students. Nonetheless, the study resulted in no correlation between life events and persistence and no correlation between gender and persistence. Work commitments were slightly correlated to persistence. However, the study did not clearly define what was meant by the term "work commitments." The study 
polled students already enrolled in study, excluding potential students that may not have the resiliency to enroll.

Kemp's (2002) study was loosely related to another resiliency study by Walberg (1997) which researched the characteristics of the resilient student that had family support and that relationship to overall educational resilience. Kemp's study design and content were found to be the most closely related recent study to the present investigation in adult student barriers to (a) persistence and (b) coping strategies. Kemp's study did not include commencement factors as noted earlier, and it strictly involved distance education. Therefore, it leaves a gap for study, that being the resiliency of the undergraduate nontraditional student in the classroom.

\section{Conclusion}

The importance of analyzing theory related to undergraduate nontraditional student barriers to persistence along with related coping strategies (including resiliency) is to give an indepth picture of the mechanisms needed to assist the adult student from an institutional perspective. If barriers are studied without inclusion of coping strategies, then one does not understand the full consequences of the barriers. Though some barriers may be prevalent with nontraditional students, those barriers may or may not be easily overcome or coped with. Some students may have a more difficult time coping with a lack of child care than they do coping with a barrier of time management. Therefore, relationships that exist between barriers and coping strategies are a necessity when trying to understand what is necessary to assist nontraditional students overcome barriers both to commencement and persistence through their undergraduate programs of study.

This investigator has found no known research existing that reports barriers and then also reports how students cope with either having or not having the barriers present when it comes to 
commencement to an education program. Such a study may help find learners that have commencement barriers and thus fail to enroll in a program of study. Nontraditional students overcome many barriers before they enroll, and if barriers are only studied after enrollment, the results may not be all-inclusive. Additionally, students who enroll in a program of study may have likely displayed resiliency characteristics and/or a propensity to cope well. Study of commencement barriers is not an element of this study as such research requires a separate population of participants that are not yet enrolled in a program of study.

There is a need to be more inclusive of males. Program completion rates for males and females vary nationally based on many factors including enrollment status as either part-time or full-time, marital status, financial aid obtainment, and whether there are children living at home. A study by Taniguchi and Kaufman (2005), found that male and female nontraditional students often have different and sometimes conflicting reasons for not completing their undergraduate degrees. For example, they found that obtaining financial aid loans increases a male's chance of degree completion but has no substantial influence on a female's completion rate (Taniguchi \& Kaufman, 2005). Institutions concerned with overall degree completion rates thus should be receptive to knowing the differences in gender that determine degree completion rates. This investigation incorporated both male and female participants proportionally based on nontraditional enrollment statistics at the Regional Learning Alliance campus and additionally details specific demographic data related to each gender.

The assumptions for this current investigation hold that research does not extend far enough beyond identification of barriers. The existing studies in the literature outline barriers with further exploration into the reason for the barriers but rarely continue exploration of both persistence and coping strategies. This research details nontraditional learner perceived barriers 
to persistence through an educational program, detailing the relationships of the resulting coping strategies they utilize to deal with those perceived barriers. This chapter serves to explain how the existing literature and research supports and/or does not support these basic assumptions. Additionally, much study design does not allow the best recognition of both barriers and coping strategies because primarily quantitative methods are used. Although quantitative data have been incorporated, this study included qualitative methods which allowed invitation of more barriers and coping strategies. This theory review and analysis is a basis for this study and will additionally explain the plan to conceptually expand these assumptions. 


\section{CHAPTER 2}

\section{METHOD}

This chapter will attempt to validate the purpose and hypothesis. The purpose of this dissertation is to identify the perceived barriers to persistence and the coping strategies for nontraditional students enrolled in a variety of adult undergraduate programs in one collaborative campus. Then, further investigation will determine if relationships exist between the perceived barriers to persistence through a variety of undergraduate adult education programs for nontraditional learners and the resulting coping strategies. Finally, if relationships do exist, to what extent do they exist? The hypothesis is that (a) relationships will exist between various perceived barriers for nontraditional students and coping strategies, and (b) the extent to which relationships exist between perceived barriers and coping strategies will vary across barriers.

\section{Methodology}

The chapter will entail method design that includes sampling, survey and interview design, data collection, data analysis approaches, and anticipated results. The sampling method is detailed in the following sections. Measurement includes the materials and instruments and how they were used in this study. Therefore, this chapter focuses on measuring/surveying the participants and how the results are analyzed and reported. There is a two-method approach to this research. First, surveying has been used via a participant-completed written survey. There were 100 participants that completed the survey of which 70 were female and 30 were male to replicate the gender ratio of undergraduate students enrolled at the Regional Learning Alliance. Surveys determined (a) demographic information about the participants, (b) internal barriers each participant had, and (c) external barriers each participant had. 
Secondly, 32 of the 100 survey participants were selected for an interview. There were 22 females and 10 males selected to replicate the undergraduate gender ratio of the Regional Learning Alliance. A survey question asked the willingness of participants to take part in a follow-up interview. There were 76 of the 100 that agreed to an interview and thus the 24 that declined an interview were not considered. The interview consisted of a set of coping strategy questions which related to the listed barriers revealed in the survey. The questions were structured the same and were open-ended, allowing a wide range of responses. Each participant response was coded to categories before being put into a matrix format to display totaled responses. The interviews assisted in expanding the details of both barriers and coping strategies in an effort to go beyond simply identifying barriers. The survey design in this chapter specifies how these data were collected, where they were collected, when they were collected, and how the survey was designed to measure the hypothesis being tested.

The survey used fit within the time constraints of the students participating while in class and required participants to complete during regular class time. Ethically-sound measures were designed, and an explanation of all sampling and measures will follow within the sections of this chapter. These measures were submitted to the WVU Institutional Review Board, and approval was granted. The findings from this methodology are detailed in the Results Chapter 3 .

\section{Population}

The population of nontraditional students across the nation is estimated to be 44 percent of the 17.1 million undergraduate students (Kazis et al., 2007). Virtually all institutions of higher education, both community college and universities, have nontraditional students enrolled in virtually all programs of study. In western Pennsylvania, there are many institutions of higher education. This study took place at a collaborative campus, the Regional Learning Alliance in 
Cranberry Township, Pennsylvania. This collaborative campus is a national model which combines 12 educational institutions into one campus. The total campus population is $73 \%$ nontraditional students. There is a variety of technical schools, four-year colleges, and universities that offer degree programs at this campus. This study included six of the institutions and their undergraduate programs at the campus to achieve a broad range of nontraditional students in one collaborative campus.

Participants and Setting

Participants in this study consist of nontraditional students enrolled in a variety of educational programs in six of the educational institutions which have regional campuses at the Regional Learning Alliance. The institutions are Carlow University, DeVry University, Geneva College, LaRoche College, Pittsburgh Technical Institute, and Strayer University. The programs include associate and bachelor degree programs in the disciplines of education, leadership, communication, business, health care, and other areas. The number of participants in the survey was 100 and the number of participants in the interview was 32 . The 32 interviewed participants represent $10 \%$ of the total of 320 undergraduates from the student population at the Regional Learning Alliance. Graduate students were excluded from this study. Graduate students have prior higher education experience, and incorporating them into to this study could easily bias the results regarding coping strategies. All students that took part in this study will fit the standard of a nontraditional student in that they were 25 years old or older and out of school for a total of 5 or more years. All students that defined themselves into this category were eligible to take part.

The process of sampling is designed to be representative of the population described above in that nontraditional students are enrolled in a wide variety of programs and in a wide variety of institutions, including technical schools, four-year colleges, and universities. This 
process was planned to consider all viable factors that may influence or bias the sample. Nonprobability sampling was avoided so that the most accurate sampling methods, size, and other factors were used. The results from sampling and methods used to design the sampling were constructed to generalize to other similar situations. The sample participant demographic information compares to that of the population. Any differences are described in the Discussion Chapter 4.

\section{Survey Design}

The survey was developed using questions based on multiple research outcomes of other studies mentioned in the Literature Review in addition to a pilot study conducted by this investigator in 2006. Specific questions related to perceived barriers as reported by nontraditional students in an effort to match the purpose of this study and to reduce bias. The survey was comprehensive with a demographic set of questions and a section devoted to finding perceived internal and external barriers (see Appendix 1). Coping strategy questions were conducted via a subsequent interview.

\section{Pilot Study}

Much of the design of this study was modeled after a pilot study conducted by this investigator in 2006. The study setting was the Regional Learning Alliance campus, and 6 participants from La Roche College were included. The nontraditional students were identified by the campus Administrator and permission for participation was obtained from each student. Subsequent interviews followed. Previous research review was conducted prior to the interviews to guide the design of questions asked during the interviews. One-on-one interviews were the sole survey method, and each lasted thirty minutes. They were then transcribed verbatim by this investigator. Emerging categories were revealed for both perceived barriers and coping strategies 
as the transcriptions were coded into matrix form. This study was a test to determine if (a) the questions were appropriate to discovery, (b) the questions were worded such that participants could easily understand and respond, (c) to find if enough information could be revealed from the participants to answer the research questions, (d) to reveal any concerns that would need to be resolved prior to a larger study, and (e) to answer the research questions which mimic the questions in this study. It was determined in the pilot study that participants did not fully understand the words "barriers" and "coping strategies." Additionally, it was determined that much of the information could have been more easily obtained from a survey rather than solely an interview. Therefore, these determinations were incorporated into this investigation, including the use of the word "obstacles" instead of "barriers." Instead of explaining the definition of “coping strategies," participants were simply asked how they coped with each obstacle. This investigation incorporates a survey and a subsequent interview as the design which were largely formed as an outcome of the previous pilot study.

\section{Interview Design}

The interview was designed as a follow up to the survey. It was a personal one-on-one interview with each participant conducted either in-person or via the telephone. Thirty-two students were interviewed, and this investigator was guided by the following instructions:

1. The interview should take no longer than 15 minutes.

2. Please ask the questions in order.

3. Explain to each participant that the interview will be used to satisfy dissertation requirements as well to understand more about the Regional Learning Alliance adult student population.

4. Explain that their responses will remain completely anonymous.

5. Explain that the interview will be recorded for transcription purposes and that after transcription, the interview will be destroyed.

6. Set the recorder and the time and begin. 
The interview time limit of 15 minutes per participant was applied as much as possible to get through 8 questions. These 8 questions included 2 related to barrier identification that may not have been identified in the survey and to confirm the barrier responses participants identified in the previous survey. The 8 questions were structured to obtain a comprehensive list of all coping strategies participants utilized to deal with the recognized barriers. No interview lasted longer than 15 minutes. Interview questions are in Appendix 2.

\section{Procedure}

A "Permission to Use Human Subjects" form was be submitted to West Virginia University Institutional Review Board (IRB) for approval before the start of the data collection process, and permission was subsequently granted. The procedures used in this study start with the permission of the educational coordinators for each participating institution at the Regional Learning Alliance. Their approval and cooperation, along with that of each class instructor, was necessary to conduct this research. The approved "Permission for Educational Research" form was distributed to each Educational Administrator for each academic institution. The forms were then collected. Had completed forms not been received from the institutions selected for this investigation, their participation would have been halted in this research study.

There was a preceding explanation of the purpose of this survey in general terms that was explained in an effort to not bias the participants. Survey participation was strictly voluntary and was administered face-to-face during regular class time. Just prior to distribution of the survey, all students were asked to raise their hands as a signal of approval if they (a) wish to participate, and (b) meet the criteria of being 25 years of age or older and have been out of formal education for 5 or more years. The surveys were then distributed to those willing to participate and were collected before the end of each class. Any student that did not take part due to absence from the 
particular class was excluded from participation. There were 100 surveys collected. Surveys were then placed into two categories based on those agreeing and not agreeing to a subsequent interview. There were 32 total applicants selected randomly from those that agreed to an interview. The total undergraduate population at the Regional Learning Alliance is 320 students and therefore, 32 represents $10 \%$ of the population. Of the 32 participants, 22 were female and 10 were male which represents the total campus undergraduate population by gender, which is currently approximately $70 \%$ female and $30 \%$ male. Applicants by gender were randomly selected since more than 32 agreed to an interview. Participants that agreed to an interview but failed to respond to requests either via email or telephone for an interview, were excluded from the interview and other random participants that agreed to an interview via the survey were selected. Additionally, surveys left blank would have been eliminated from the participant pool, however, all surveys distributed were completed.

\section{Validity of Instruments}

Validity of each question in the survey and subsequent interview are detailed in Results

Chapter 3. The nature of this study dictates the type and level of validity issues that require a level of justification. This research study attempts to overcome areas of concern relative to content validity that was previously presented in related research studies discussed in the Literature Review. Perceived content validity is disclosed in the results section. If for example, a participant stated he/she has reservations about the validity of a specific question, that statement is disclosed in the results section. The survey in Appendix 1 has demonstrated perceived content validity to three former nontraditional students that did not participate in this investigation but are affiliated with the Regional Learning Alliance. These individuals work in an administration role at the campus, and each began their undergraduate degree programs classified as a 
nontraditional student as previously defined. Each of them reviewed the survey questions and the format in which they are presented in Table 1 . The feedback received from each of them stated that the survey instrument appears logical. None offered additional suggestions for revision.

Content validity is based on the extent to which a measurement represents the specific intended domain of content (Carmines \& Zeller, 1991). Six adult education administrators that represented each of the six institutions that participated in this investigation were asked to review both the survey instrument and the subsequent interview questions. The administrators are considered experts in the field of adult education. All stated that they believed the instruments to be valid and the questions necessary. One of the experts questioned the ability to calculate results and show any relationships. However, he did not have any concerns about the specific questions involved, nor did he express any concern with the format of the survey with subsequent interview. One expert questioned the qualitative versus quantitative nature of the study and asked for further explanation. Once the process of the study was explained to the expert, she complemented the investigation design. Thus, content validity, a qualitative measure, was confirmed with these field experts.

There is no single measure of construct validity (Yaghmale, 2003). The construct validity of a survey instrument measures how well the instrument performs in practice from the standpoint of the specialists who use it. Construct validity is based on the accumulation of knowledge about a test (or survey) and its relationship to other tests and behaviors. In order to confirm the construct validity of this research design, an assessment was made based on a pilot study this investigator conducted in 2006. This assessment confirmed elements of construct validity. The pilot survey questions that challenged construct validity were modified for this study and are shown in final format in Appendix 1. Additionally, it should be known that 
assessment of the construct validity requires practical use of the survey instrument in various settings (Yaghmale, 2003). The limitation of the pilot study was that it was practiced in only one setting and with one academic institution.

Difficulties with assessment of the construct validity in these survey instruments are that there may not necessarily be a measurable "true" value of the traits that are qualitatively measured since many of the barriers are considered perceived (rather than real). Construct validity judgment is also based on the accumulation of and evaluations of related numerous studies using similar instruments with similar format. These studies have been evaluated and reviewed in Chapter 2. Any threats to the reliability of a test (survey) are also threats to its validity because a test cannot be said to be any more systematically valid than it is first systematic (Yaghmale, 2003). Reliability of instruments are discussed in Chapter 3. Specific Methods for Demographic Data Collection

Demographic data were collected via the survey. Though nontraditional students were identified in classes prior to survey distribution, specific demographic information was a portion of the survey. For example, the survey asked students to, "Please select age range." If the age range selected would have been below age 25 , the student would have been eliminated from the study. No student under age 25 completed the survey. Barrier questions on the survey followed the demographic section. The demographic data helps to explain relationships. For example, if child care were listed as a barrier, there could be a much stronger relationship if we knew how many children the participant has and the ages of those children. Other demographic information relates to a participant's age, employment status, number of work hours per week, the financial range for the participant's household, and whether or not their enrollment in an education program was voluntary, mandatory for employment, or for other reasons. Other related questions 
were included in this survey. The survey is more quantitative than qualitative with the exception of open-ended barrier questions and role question. The survey is listed as Appendix 1.

\section{Data Analysis Procedures}

Data analysis is a mixed methods design. Each completed survey (Appendix 1) was analyzed by inputting the results into a spreadsheet. The categories of barriers were input into the left side of a matrix, including any barriers that were listed, rather than selected, by participants. Internal and external barriers were formatted on separate matrixes. Coping strategies were listed on the top of a separate matrix. Demographic data were also put into a matrix format. The interview was a qualitative content analysis.

Analyzing coping strategies was accomplished via individual participant interviews as noted in Appendix 2. The interviews were conducted by this investigator and recorded. All answers were then coded into categories. All interview data were analyzed using the constant comparative method of analysis, as outlined by Glaser and Strauss (1967) to group answers to common questions and analyze different perspectives on central themes. The responses were put into emerging categories or themes deemed "core categories." Categories, in turn, were analyzed for properties, similarities, and differences. For example, if a participant stated that she coped with the barrier of "Lack of Motivation" by "getting mental support from her coworkers," the response was put into the core category, "Encouragement by Co-Workers." This was the method used to code the interview data. This investigator coded the data with assistance from a campus administrator for the first 8 interview participants. Both listened to the recordings and coded answers separately for comparison. Review followed to subsequently compare the coded participant responses. Agreement was then confirmed. After all data were categorized and coded, the results were tallied. The categories were then organized from most prevalent to least 
prevalent. Least prevalent equals at least two responses. The matrixes were completed after all interview results were coded. The results are analyzed and reported in Results Chapter 3. The next chapter assists in detailing (a) if relationships exist between each barrier and specific coping strategies and (b) to what extent.

Anticipated Results and Implications

Anticipated results for this study included recognizing a full scope of barriers for nontraditional students and encompassing coping strategies. While both barriers and coping strategies were discovered, it was additionally anticipated that there would be specific prevalent coping strategies related to each barrier. It was believed that there would be both strong and weak relationships between certain barriers and coping strategies. The results additionally hoped to reveal a more thorough understanding of the barriers adult students face with correlation to coping strategies. Thus, the results are unique to any other known studies and perhaps reveal more about nontraditional students than previous singular studies related to either barriers or coping strategies. 


\section{CHAPTER 3}

\section{RESULTS}

The findings from the analyses described in the previous chapter are presented in detail in this chapter. These results will be organized in the following manner. The first section is comprised of demographic participant information. This will include the information obtained from the participant survey that answers Research Question 1. This question specifically states the following. What are the perceived barriers to persistence for nontraditional learners enrolled in a variety of adult undergraduate programs? The data presented include (a) general demographic information, (b) internal barriers to persistence, and (c) external barriers to persistence. The second section of this chapter is comprised of (a) information about the content validity, construct validity, and inter-rater reliability and (b) description and overview of the interview process. The third section will contain results pertaining to Research Question 2. This question specifically states the following. What are the coping strategies related to the perceived barriers for nontraditional learners enrolled in a variety of adult undergraduate programs? The data presented includes (a) coping strategies related to internal barriers and (b) coping strategies

related to external barriers. The fourth section contains results pertaining to Research Question 3. This question specifically states the following. Do relationships exist between perceived barriers to persistence and coping strategies for nontraditional learners enrolled in a variety of adult undergraduate programs, and if they do exist, to what extent? The information presented includes a presentation of the results of the interview with relationship data.

Demographic Participant Information 
The participants in this study were all undergraduate students, age 25 or older, enrolled in one of 6 different institutions, and having been out of formal education for 5 or more years. The 6 schools include a technical school offering a variety of undergraduate technical degrees, 3 forprofit educational institutions, and 3 not-for-profit traditional institutions of higher education. The 3 not-for-profit were private institutions with RLA campus enrollments ranging from 44 to 162 total students. Participants include both full-time and part-time students. Full-time students were defined by the credit hours enrolled. Credit hours of 12 or more per term were considered full-time for the purpose of this study. There were a wide variety of majors participating in this study across many disciplines as outlined in Table 1. Participants included those employed and not employed. Employed participants include both part-time and full-time as outlined in Table 1. The demographic information from the survey outlined in Table 1 also includes participant primary reasons for continuing their education, other roles they perform, if they are able to use work time for class, race and ethnicity, relationship status, and the number of children living at home. 
Table 1

Demographic Participant Information

Topics Frequency $\quad(n=100)$

1. Institution

$\begin{array}{ll}\text { A } & 20 \\ \text { B } & 22 \\ \text { C } & 20 \\ \text { D } & 24 \\ \text { E } & 8 \\ \text { F } & 6\end{array}$

2. Program of Study

Nursing

Business 16

Leadership 15

Accounting 12

Non-Major or No Major Listed 9

Organizational Development

Computer Science or Related Technical 6

Human Resources 6

Medical Other (Radiography, Imaging, etc.) 4

Community Ministry 2

Degree Completion 1

Liberal Studies 1

Education (K-12) 1

Pre-Law

Professional Writing 1

20

22

20

8

6

1

1

1

(1)

3. Gender

Female

Male

30

4. Age Range

$\begin{array}{ll}25-34 & 45 \\ 35-48 & 39 \\ 49+ & 16\end{array}$

Table 1 continues: 
Table 1 continued:

Demographic Participant Information

Topics Frequency $\quad(\mathrm{n}=100)$

5. Undergraduate Rank

Senior

Junior

Sophomore

Freshman

No Rank Given or Not Known

6. Relationship Status

Married/Partnered

Single

Divorced

Widowed

7. Children at Home

Yes

1 Child

2 Children

3 Children

4+ Children

No

37

23

16

13

11

63

14

23

0

41

11

20

3

7

59

8. Ethnicity

Not Hispanic or Latino

Hispanic or Latino

2

9. Race

White

Black or African American

American Indian or Alaskan Native

Asian

Native Hawaiian or Other Pacific Islander
96

3

1

0

0

10. Enrollment Status

Full-Time (12 or more credit hours)

Part-Time (less than 12 credit hour)

Not-Specified

Table 1 continues: 
Table 1 continued:

Demographic Participant Information

Topics Frequency $\quad(\mathrm{n}=100)$

11. Years Out of Formal Education

5-10

66

$10+$

33

Not answered

1

12. Employment Status

Employed 79

$37+$ hours per week

21-36 hours per week

13-20 hours per week

1-12 hours per week

60

17

2

Not Employed

21

13. Ability to Utilize Work Time for Class Preparation or Study

Yes

$<1$ hour per week

1-2 hours per week

4

2-3 hours per week

3-4 hours per week

$>4$ hours per week

24

No

Not Answered

6

6

3

5

58

18

14. Primary Reason(s) for Education*

Personal rewards such as self esteem

44

To seek new employment in different career field

42

To become promoted with current employer

To stay in my current career field but seek new employer 22

To stay in my current position but receive raise 15

Career goals not associated with financial goals 14

Family related reasons

Other: Open a business, just to learn, ministry

7

My employer requires that I continue my education 5

Table 1 continues: 
Table 1 continued:

Demographic Participant Information

$\begin{array}{lll}\text { Topics } & \text { Frequency } & (\mathrm{n}=100)\end{array}$

15. What Other Roles Besides Being a Student,

Parent, Spouse, or Employee Do You Have?

No other roles $\quad 56$

Volunteer for clubs/organizations/civic/charities 20

Church (pastor, teacher, leader, or member) 11

Coach or referee 6

School board or PTO 3

Mentor or counselor $\quad 3$

Military

Babysitter

3

Emergency Services $\quad 1$

Business Owner 1

3

Note. *Participants were instructed to choose all reasons that apply to them and thus more than one response was allowed. 
Internal Perceived Persistence Barriers

The survey included a definition and description of perceived internal barriers before asking participants to rate how they were affected by each barrier listed. A simple Likert scale was presented to determine the level that each potential perceived barrier was experienced by each participant. The question was presented to participants in the following manner:

“Internal obstacles are psychological challenges one may face when enrolled in a program of study. The following are typical internal obstacles experienced by nontraditional students after they enroll in a program of study. Please indicate the level to which each affects (or has affected) you in your current role as an adult student. Do not consider any obstacles that you had PRIOR to enrollment that disappeared after your first class.”

Participants then were presented with the list of potential perceived internal barriers with the following directions.

"Please indicate to what extent each obstacle has affected you on a scale of 0 to 5, with “0” being Not Affected At All and "5” being Strongly Affected:”

After each participant responded, the next question posed to them included the opportunity for them to list any potential perceived internal barriers they have experienced that were not listed in the above question. The following was presented to participants.

"The above list may not have declared all internal obstacles you face as an adult student. Therefore, please list below any other internal obstacles that affect (or have affected) you. Please indicate to what extent each obstacle you list has affected you on a scale of 1 to 5, with “1” being Slightly Affected and "5” being Strongly Affected:"

Participants were given several lines to write in responses, and these responses were tabulated as listed in Table 2 . 
Research Question 1 specifically states the following. What are the perceived barriers to persistence for nontraditional learners enrolled in a variety of adult undergraduate programs? Table 2 reports the determination of this question related specifically to internal barriers for participants. The internal barriers are listed in order of most to least prevalent among participants in the study. Participant responses with a " 0 " or " 1 " Likert scale ranking for each internal barrier, were omitted from the table, as any rating below a " 2 " was considered to be of little to no substantial effect on the participant. Internal barriers are reported in the following table (Table 2). 
Table 2

Perceived Internal Barriers to Persistence

Topics Reported as 2-5 on Scale

1. Test anxiety $\quad 62$

$\begin{array}{ll}\text { 2. Writing anxiety } & 60\end{array}$

3. Worry about ability to fulfill family obligations 55

4. Worry about ability to fulfill career obligations 55

5. Worry about inability to learn the material taught 55

6. Fear of failure $\quad 54$

7. Lack of motivation $\quad 53$

8. Insufficient academic skills/preparedness 42

9. Apprehension about fitting in 32

10. Apprehension about meeting peers and/or making friends $\quad 30$

11. Others:

Time management 2

Health issues $\quad 2$

Public speaking 1

Overall anxiety 1

Lack of sleep 1

Anxiety about school loans 1

Being a single parent 1

Lack of income 1

Anxiety about job search $\quad 1$

Anxiety about lack of technical skills $\quad 1$ 


\section{External Perceived Persistence Barriers}

The survey included a definition and description of perceived external barriers before asking participants to rate how they were affected by each barrier listed. A Likert scale was presented to determine the level that each potential perceived external barrier was experienced by each participant. The question was presented to participants in the following manner.

“In pursuing your current undergraduate program of study, please select any external obstacles you may have experienced once you began your first class (please circle ALL that apply). External obstacles are challenges presented by your environment that you have faced. Please select all that apply, regardless if they are (or were) real or perceived."

Participants then were presented with the list of potential perceived external barriers with the following directions.

"Please indicate to what extent each obstacle has affected you on a scale of 0 to 5, with "0” being Not Affected At All and "5” being Strongly Affected:"

On Table 3 the external barriers are listed in order of most to least prevalent among participants in the study. Participant responses with a " 0 " or " 1 " Likert scale ranking for each external barrier listed were omitted from the table as any rating below a " 2 " is considered to be of little to no substantial effect on the participant. After each participant responded, the next question posed to them included the opportunity for them to list any potential perceived external barriers they have experienced that were not listed in the above question. The following was presented to participants.

“The above list may not have declared all external obstacles you face as an adult student. Therefore, please list below any other external obstacles that affect (or have affected) you. 
Please indicate to what extent each obstacle you list has affected you on a scale of 1 to 5 , with "1" being Slightly Affected and "5” being Strongly Affected:”

Participants were given several lines to write in responses, and these responses were tabulated as listed in Table 3. External Barriers are reported in the following table (Table 3).

Table 3

Perceived External Barriers to Persistence

$\begin{array}{lll}\text { Topics } & \text { Reported } 2-5 \text { on Scale }\end{array}$

1. Lack of spousal/partner support

2. Lack of other family support (i.e., children, parents)

3. Lack of employer support

4. Ability to finance my education

5. Lack of acceptable child care options

14

6. Distance of classroom

7. Design of program 32

8. Inability to meet program entrance requirements

18

9. Lack of feasible degree program options

10. Others:

Death in the family 


\section{Validity}

The next portion of this chapter pertains to validity as previously detailed in Chapter 2 . Specifically, this chapter discusses validity as perceived by participants and as it pertains to the reliability of instruments used in this study. Inter-rater reliability is also discussed as it pertained to the interview process. A discussion of the interview process is thoroughly explained.

Surveys were distributed to participants that qualified for this study by being at least 25 years of age and having been out of formal education for at least 5 continuous years. After surveys were distributed, this researcher asked that any participant please raise their hands during completion of the survey if they had questions, did not understand a question being asked, or had any comments related to the survey itself. There were a few times that participants did raise their hands to ask a question. A few of the questions they posed to this researcher were related to understanding if they should respond if any of the barriers did not apply to them. Instructions stated to please answer " 0 " for any barrier that does not have any effect at all on the participant, and less than 5\% asked for clarification on that instruction. Other participants asked if they needed to complete the entire survey. They were told that the entire survey did need to be completed in order to have complete responses. No participants made comments related to the validity of the demographic or barrier questions.

A previous pilot study was conducted as a measure of content validity as detailed in Chapter 2. An expert and professor in qualitative research at West Virginia University Department of Educational Psychology reviewed the instruments used and provided guidance for necessary changes to the instruments both prior to participant interviews and after the pilot study. The final survey and interview instruments used in this study were the result of expert analysis from the pilot study. Accordingly, the instruments have content validity. In the following 
section, reliability coefficients for scales in surveys are an important indicator for the dependability of instruments.

\section{Reliability}

The purpose of reliability is to illustrate the consistency of a measure in order to demonstrate that what the research says can be replicated. With a purely quantitative study, it is much easier to test for reliability. There are many variables in this qualitative study, making it more difficult to demonstrate certain types of reliability. Reliability tests such as the Chronbach's Alpha for internal consistency and the Test-Retest were not appropriate measures of reliability for this study because this was not a scale using a single construct. Inter-rater reliability however, was the appropriate method of reliability in this study. According to Marques and McCall (2005), inter-rater reliability should not merely be limited to a verification tool for quantitative research, but it should also be applied as a solidification strategy in a qualitative analysis as well.

Inter-rater reliability is the extent to which two or more individual raters (or coders) agree. The process, used to ensure inter-rater reliability, consisted of both this investigator and an administrator of the Regional Learning Alliance campus rating the first 8 interviews conducted. Both this investigator and the co-rater used phenomenological reduction to eliminate redundancies in the answers and cluster the themes that emerged from the interviews. Phenomenology is regarded as one of the frequently used traditions in qualitative studies (Marques \& McCall, 2005). According to Creswell (1998) a phenomenological study describes the meaning of the life experiences for several individuals about a concept or the phenomenon. Phenomenology reduces rich descriptions of human experience to underlying, common themes, resulting in a short description in which every word accurately depicts the phenomenon as experienced by co-researchers (Blodget-McDeavitt, 1997). This principal process was utilized for the qualitative interview component of this study. 
The phenomenological process was fairly straightforward, as participant responses all contained enumerations of relevant and clear phenomena. To clarify this with an example, a participant was asked, "You mentioned that you had an internal obstacle (barrier) of fear of failure. Can you tell me how you coped with this obstacle (barrier).” The participant responded with, "My husband gives me encouragement by telling me that I can make it through." Therefore, the data were coded as Encouragement by Spouse/Partner. Inter-rater reliability was applied to this study by initially attaining themes by the co-raters before formulating any conclusions based on themes. After the first eight interviews were rated (or coded) by this Investigator and co-rater, a simple comparison was made to determine if participant responses were coded in a similarly consistent manner. While there were some differences in the language used by each rater, the definitions of terms utilized were consistent. This Investigator did have 6 additional themes emerge than the co-rater for some of the 8 participant interviews. For example, a participant responded to a question by stating, "I am not involved with my kids' activities now, and thus my wife is having to do most of it." This investigator coded the response as "Depend upon spouse/partner more" and "Have less quality time with family." The co-rater response was "Depend upon spouse more often." While both coded the same response, this Investigator found an additional theme emerge from the participant response related to having less quality time with family.

There were a total of 6 questions that produced 6 additional themes from 71 questions and 98 themes from the first 8 interview participants. The co-rater found 91 agreeing themes. The researcher in a phenomenological study always ends up with an abundance of themes on his or her list since he or she manages the entirety of the data (Marques \& McCall, 2005). There were no instances of complete disagreement and no instances of coding themes that could not be 
defined with the same terminology. According to Marques and McCall (2005), inter-rater reliability $=($ Number of agreeing themes $)+($ Number of disagreeing themes $) /($ Total number of observed themes). Thus, inter-reliability for this study is calculated as $=(91+0) / 98=92.9 \%$. Generally, a level of $80 \%$ agreement indicates an acceptable level of reliability (Graham, 2001). This inter-rater reliability was specifically conducted for the first 8 interviews which represents $25 \%$ of the 32 participants interviewed. According to Marques and McCall (2005), the data to be reviewed by inter-raters should only be a segment of the total number of interviews since data in qualitative studies are usually rather substantial and inter-raters usually have limited time.

Creswell (1998) suggests for a phenomenological study the process of collecting information should involve primarily in-depth interviews with as many as 10 individuals. Thus, rating the first 8 interviews in this study with a co-rater is consistent with phenomenological research. This Investigator rated (coded) the remaining 24 participant interviews. This method of verifying the study's findings represents a constructive way, during the process, of measuring the consistency in the interpretation of the findings and further substantiates the study before it is too late in the process (Marques \& McCall, 2005).

\section{Interview Overview}

Interviews were conducted both in-person and via telephone. All interviews were recorded. The interview was conducted over the course of 4 months after participants completed surveys. While 100 participants completed surveys, there were 32 selected for an interview. The survey contained the question, "Are you willing to take part in a follow-up 15 minute interview?" The 100 surveys were assigned a number " 1 " through "100" and were separated into a) those that were willing to take part in an interview and, b) those that were not willing to take part in an interview. Only those that stated they were willing to take part in an interview 
were considered for an interview. Information from the survey included contact data such as telephone number and email address. In some circumstances, participants willing to take part in an interview only listed email contact information as a mode of contact. There were 32 randomly selected participants from 76 that were willing to take part in an interview. This investigator began contacting each participant individually. The first attempt to contact each participant was via email. The email reminded each participant of the survey and their agreement on the survey to take part in an interview. They were asked for 15 minutes of time to conduct an interview as a follow-up to the survey. They were given 2 options to conduct the interview, either in-person or via telephone. They were asked to list possible dates and time(s) that they would be available for an interview followed by the method they preferred it be conducted.

Eighteen participants responded to the first email interview request, all of which stated they agreed to participate. Interviews were immediately scheduled with these 18 participants. Of the 18 participants scheduled for an interview, 17 interviews were conducted. One participant agreed to a telephone interview but did not respond to the call placed on the date and time scheduled. An email was then sent to this participant, specifically asking for an alternative interview date and time. There was no response to the email, and thus no further contact with the participant was made. To obtain 15 additional interviews, the remaining participants that agreed to an interview via the survey (excluding the 18 that responded to the first email request) were emailed a second time. The email request again stated the confirmation of their expressed interest in participating in an interview related to the survey taken with an additional appeal that their time would be appreciated. There were 4 participant responses and all agreed to take part in an interview via telephone. These 4 interviews were successfully conducted, leaving 11 remaining interviews necessary to be conducted. 
The remaining 11 participants that completed a survey and originally agreed to take part in an interview were randomly selected, 6 of which only listed a telephone number and no email address. Thus, these 6 participants did not receive the previous email interview requests. Calls were placed to these 11 participants that stated on the survey that they were willing to participate in an interview. There were 8 of these participants that did not answer and/or return the call request. Messages were left with all that did not answer and had an option to leave a voicemail. Thus, the remaining 36 survey participants that stated they were willing to take part in an interview were randomly called one-by-one until 11 interviews were arranged. There were 3 that did not appear for scheduled in-person interviews. There were 2 that did not answer the call on the arranged date and time for a telephone interview. However, this Investigator continued to make calls to the remaining participants that originally agreed to an interview until the 11 additional interviews were complete. Of the 11, 9 were conducted via telephone and 2 in-person. There remained 12 potential participants willing to take part in an interview, according to the survey, that were not contacted due to the attainment of 32 interviews.

The interview process was scheduled for 15 minutes. However, there was no limit placed on time needed to ask each participant the questions associated with coping strategies related to the internal and external barriers listed on each individual survey. No interviews however, lasted beyond the 15 minutes scheduled. Interviews lasted anywhere from 3 minutes to 15 minutes. The length of interview time was related to a) the total number of barriers listed on each survey, b) the specific participant's length of time taken to answer each question and c) if the interviews were in-person or via the telephone. While time comparisons were not made for all interviews, overall, in-person interviews lasted slightly longer than the telephone interviews. There were 3 questions asked for each barrier the participant listed on the survey. Thus, the number of 
questions for each participant varied and so did the time required for each interview. Those that were asked more questions required more time to answer. Additionally, there were some participants that answered the questions with short and succinct responses. Others gave longer answers with extensive explanations.

\section{Coping Strategies for Perceived Barriers}

Research Question 2 specifically states the following. What are the coping strategies related to the perceived barriers for nontraditional learners enrolled in a variety of adult undergraduate programs? The data presented in Tables 4 and 5 include coping strategies related to internal barriers and external barriers, respectively. Perceived barriers listed on each individual survey with a rating as 2 to 5 on a scale of 0 to 5 were integrated into the subsequent interview for 32 of the 100 survey participants. Participants were asked what coping strategies were used for each of the perceived internal and external barriers listed on their individual surveys. Perceived barriers rated as "0" or " 1 " were omitted from the subsequent interview as those ratings either did not at all affect the participant or rarely affected them. Table 4 shows the perceived internal barrier with each related coping strategy given by participants. Each mean barrier score is reported. Only coping strategies used by two or more participants have been included on the table. Table 4 includes a listing of the number $=\mathrm{n}$ of times each specific coping strategy was reported by those participants interviewed. Additionally, each participant was asked whether the coping strategy they used was effective or ineffective for the specific perceived barrier they had. In some cases, participants stated that the coping strategy used was "neither" effective nor ineffective. Therefore, those responses are also reported in both Tables 4 and 5 . In other cases, participants stated the coping strategy used was "both" effective and ineffective. When such responses were given, both "effective" and "ineffective" responses were scored. 
Table 4

Coping Strategies Related to Internal Barriers to Persistence

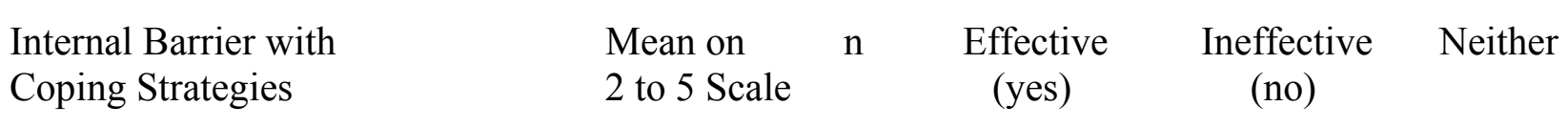

1. Text anxiety

3.5

Worry/become stressed

Forget the material when taking a test

Become nervous

Become physically ill

Listen to music before an exam

Study for tests more than necessary

$\begin{array}{lll}6 & 2 & 4 \\ 6 & 0 & 6 \\ 3 & 1 & 3 \\ 2 & 0 & 2 \\ 2 & 2 & 0 \\ 2 & 2 & 1\end{array}$

2. Writing anxiety

3.6

Have friends/family/peers assist and review my assignments before I submit them

Utilize the RLA Writing \& Research Center for assistance

Ask for help/assistance from instructor

Depend on mentor/coworkers/family/friends for encouragement to finish a writing assignment

family obligations

Spend less time with family

Attend less family activities

Depend on partner to handle more family obligations

Manage my time in order to handle family obligations

Communicate more with family via phone, text, email instead of in-person

Ask for patience and understanding Miss class sessions for family obligations Sleep less in order to fill family obligations Worry

$\begin{array}{lll}7 & 7 & 1 \\ 3 & 3 & 0 \\ 2 & 2 & 0 \\ & & \\ 2 & 2 & 0 \\ & & \\ & & \\ 13 & 6 & 6 \\ 6 & 2 & 6 \\ & & \\ 3 & 2 & 2 \\ 3 & 3 & \\ & & 0 \\ 3 & 3 & \\ 3 & 2 & 1 \\ 2 & 0 & 2 \\ 2 & 2 & 1 \\ 2 & 1 & 1\end{array}$

Table 4 continues: 
Table 4 continued:

Coping Strategies Related to Internal Barriers to Persistence

Internal Barrier with

Coping Strategies
Mean on $\mathrm{n}$

2 to 5 Scale
Effective

(yes)
Ineffective Neither

(no)

4. Worry about ability to fulfill

career obligations

Work normal hours and adjust class schedule

around career/Do not allow school to

affect job

$\begin{array}{lll}4 & 3 & 1\end{array}$

Talk to professors about work obligations

Get too little sleep

$3 \quad 3 \quad 0$

Mask academic-related stress, lack of sleep, etc. to my employer

32

2

Get behind or am unable to complete duties 3.1

5. Worry about inability to learn the material taught

Study (more) until I learn the materials Confer with peers to gain an understanding

Read the material/books more than once to fully understand the material

Get behind during class

Struggle because of difficulty level of class

2
2

\section{7}

6. Fear of failure

Anxiety/worry

2

2

0

Taking one step at a time to success

Help from faculty

4

3

3

2

2

1


Internal Barrier with

Coping Strategies
Mean on

2 to 5 Scale
Effective
(yes)

Ineffective

(no)

9. Apprehension about fitting in

2.9

Communicate with peers and professor in an effort to fit in (talk about apprehension) 7

Play roles within class (i.e., mother, task leader, comedian)

I am unable to fit in with my peers

$2 \quad 1$

7

0

$2 \quad 2 \quad 0$

10. Apprehension about meeting peers and/or making friends

Initiate communication with peers

Do not make friends (or easily)

2.5

Do not have time or need to make friends

$\begin{array}{lll}8 & 7 & 1 \\ 3 & 1 & 2 \\ 2 & 1 & 1\end{array}$

Note. Table 4 includes a listing of the number $=\mathrm{n}$ of times each specific coping strategy was reported by interviewed participants. Each participant was asked whether the coping strategy used was effective or ineffective for each specific perceived barrier. In some cases, participants stated that the coping strategy used was "neither" effective nor ineffective or "both" effective and ineffective. Those that answered "both" were scored equally in each. 
The data presented in Table 5 include coping strategies related to external barriers. There

were 32 participants interviewed.

Table 5

Coping Strategies Related to External Barriers to Persistence

External Barrier with

Coping Strategies

$\begin{array}{llcc}\text { Mean on } & n & \begin{array}{c}\text { Effective } \\ \text { (yes) }\end{array} \text { to } 5 \text { Scale } & \begin{array}{c}\text { Ineffective } \\ \text { (no) }\end{array}\end{array}$

1. Lack of spousal/partner support

3.1

Ignore/disregard/nothing I can do

I don't have a spouse/partner which is why I lack support

$2 \quad 2$

Argue frequently with spouse/partner about things I am unable to do because of school 2

2. Lack of other family support $\quad 3.1$

I rarely discuss education since my family does not care to give any support

I accept that I am unable to rely on my children and/or parents for support

3. Lack of employer support $\quad 3.0$

I take out loans or pay from savings

I make sure that classes do not interfere with my job

6

3

3

$2 \quad 1$

$$
\text { with my job }
$$

4. Ability to finance my education

I have to secure student loans

3.1

I pay for school with savings

$\begin{array}{llll}4 & 1 & 2 & 1 \\ 3 & 3 & & \end{array}$

I worry about having to repay loans

$\begin{array}{lll}9 & 6 & 4 \\ 3 & 3 & \\ 2 & & 2\end{array}$

5. Lack of acceptable child care $\quad 2.3$

There was no more than 1 response for each coping strategy reported and therefore, no common coping strategies were used 
Table 5 continues:

Coping Strategies Related to External Barriers to Persistence

\begin{tabular}{|c|c|c|c|c|}
\hline $\begin{array}{l}\text { External Barrier with } \\
\text { Coping Strategies }\end{array}$ & $\begin{array}{l}\text { Mean on } \\
2 \text { to } 5 \text { Scale }\end{array}$ & $\mathrm{n}$ & $\begin{array}{l}\text { Effective } \\
\text { (yes) }\end{array}$ & $\begin{array}{l}\text { Ineffective } \\
\text { (no) }\end{array}$ \\
\hline
\end{tabular}

6. Distance to classroom

2.8

I commute a long distance but it is still the closest campus to where I live $5 \quad 2$

Online classes do not appeal to me/I fear I would not be successful at online options 3

I am sometimes late for class due to class commute after work (or road conditions)

$3 \quad 3$

3

1

1

7. Design of program 2.8

I am forced to extend the time to finish degree due to remaining required classes taught only on same day/time

8. Inability to meet program entrance requirements 2.6

I am required to take developmental courses which extends graduation time and expenses 2

1

9. Lack of feasible degree programs 2.7

It was not the major I wanted but it fit around my work schedule

Note. Table 5 includes a listing of the number $=\mathrm{n}$ of times each specific coping strategy was reported by interviewed participants. Each participant was asked whether the coping strategy used was effective or ineffective for each specific perceived barrier. In some cases, participants stated that the coping strategy used was "neither" effective nor ineffective or "both" effective and ineffective. Those that answered "both" were scored equally in each. 


\section{Relationships between Perceived Barriers to Persistence and Coping Strategies}

The structure of this study was designed to find both the perceived barriers to persistence for nontraditional learners and the ways they cope (or coping strategies) with each perceived barrier. The intent was to find not only how nontraditional students cope with each barrier but also to determine if the ways they cope with each perceived barrier are effective or ineffective. Having a better understanding about what perceived barriers are most prevalent and what coping strategies are used, helps determine if both administrators and faculty need to teach more effective coping strategies and/or what specific barriers are most important to focus on. Research Question 3 specifically states the following. Do relationships exist between perceived barriers to persistence and coping strategies for nontraditional learners enrolled in a variety of adult undergraduate programs, and if they do exist, to what extent? Relationships between perceived barriers to persistence and coping strategies for nontraditional learners were revealed via Tables 4 and 5.

Table 4 specifically details the perceived internal barriers and the resulting coping strategies. The barrier with the highest mean for the 100 survey participants is Fear of Failure. The mean was 3.7 on a scale of 2 to 5 with " 2 " representing being somewhat effected and " 5 " representing being strongly affected. Therefore a mean score of 3 would indicate being affected, and a score of 4 would indicate being moderately affected. The mean score being closer to 4 indicates that participants were closer to being moderately affected by this perceived barrier. The subsequent interview shows the relationship between that barrier and the coping strategies used. To further explain, there were 7 of the interview participants that coped with the barrier by having anxiety and/or worry about the barrier. Of those 7, 2 stated that coping with fear of failure by having anxiety was effective while the majority, 5 , stated it was an ineffective coping 
strategy. The relationship is revealing in that most of the participants that recognized having anxiety because they have a fear of failing, also believe that using that coping strategy is ineffective.

\section{Summary}

The next portion of this chapter deals with summarization of the results related to Research Question1, Research Question 2, and Research Question 3. Research Question 1 states the following. What are the perceived barriers to persistence for nontraditional learners enrolled in a variety of adult undergraduate programs? It became apparent that internal barriers affected participants more than did external barriers. Of the 10 internal barriers listed on the survey, the barrier that affected participants the least, Apprehension about Meeting Peers and/or Making Friends, still affected more participants than did the most prevalent external barrier, Lack of Spousal/Partner Support. The most common barriers were Test and Writing Anxiety which affected 62 and 60 participants, respectively. Not surprisingly, 7 of the 10 internal barriers listed on the survey were listed as barriers that at least somewhat affected the majority of participants.

While participants had the option to list barriers affecting them that were not pre-listed on the survey, only 2 additional barriers were listed by at least two participants, time management and health issues. It is not known whether more participants would have revealed having these and any of the other self-explained additional barriers if those barriers would have been prelisted on the survey. Most of the additional listed barriers were unique to the individual students such as "death in the family," and "public speaking."

Lack of support was the overall apparent external barrier. There were 46 participants that stated they were at least somewhat affected by at least one of the 3 listed support barriers. The 
fact that nearly half of the participants stated they lacked support from either a spouse/partner, a family members such as children or parents, or their employer was congruent with recent research. The frequent coexistence of family responsibilities and commitments with the demands of academia can create additional challenges and barriers to academic success for the nontraditional female student (Carney-Crompton \& Tan, 2002). Often it is the positive support received by the nontraditional student that encourages them to persist through their educational journey. Support from family members has been found to be substantial in reducing the level of stress experienced by adult female undergraduate students in a number of studies (Plageman \& Sabina, 2010). A recent study on the persistence affected by family for the adult undergraduate female student revealed that knowing the family is supportive of their academic endeavors seems to be a factor in helping adult students persist (Plageman \& Sabina, 2010).

Research Question 2 states the following. What are the coping strategies related to the perceived barriers for nontraditional learners enrolled in a variety of adult undergraduate programs? Coping strategies that were not listed by at least 2 participants were excluded from Tables 4 and 5. If not more than one participant responded to a particular coping strategy, the coping strategy therefore was not considered to be prevalent and thus unable to show what extent relationships exist for nontraditional students as examined in the 32 participants interviewed in this study. The majority of coping strategies related to both internal and external perceived barriers for these participants were singular strategies, stated by only one participant. Therefore, trends in coping strategies are listed in Tables 4 and 5.

The coping strategies used by participants have themes that emerged throughout. Worry or anxiety was a coping strategy employed by participants for 4 barriers including Text Anxiety, Worry About Ability To Fulfill Family Obligations, Fear Of Failure, and Ability To Finance My 
Education. In fact, it was the most common strategy used to deal with the barrier fear of failure. While it may appear that developing anxiety as a coping mechanism would be ineffective, many of the participants stated that it was an effective way to deal with a barrier. Most explanations revolved around anxiety having consequences such as forcing them to study more for fear of failing a test.

Many of the barriers themselves were either apprehension or worry related. The coping strategies employed to deal with such barriers did include communication as a tool. Communication with peers and faculty was an effective strategy used by a majority of participants that had associated barriers. Communication happened in a variety of methods including face-to-face and telephone along with texting and email as other methods.

Clearly there were students that found coping strategies that were appropriate and effective while others used negative and/or ineffective strategies. Tables 4 and 5 display the specific list of coping strategies used for each barrier. While only strategies used by two or more participants were considered substantial enough to include in the reporting, there were some barriers that did not have any common strategies used by a majority of participants. The Design of Program, Inability to Meet Program Entrance Requirements, and Lack of Feasible Degree Programs were all barrier examples having just one common strategy each. Once considered a predominant barrier for primarily female students, Lack of Acceptable Child Care was not only a minor barrier for a few participants, but there were no common strategies employed. It is thus apparent that this particular barrier is not substantial for the nontraditional students at the Regional Learning Alliance campus.

Identifying coping strategies helps to then understand and consequently develop an approach that incorporates productive ways to teach students to deal with barriers they may have. 
While the goal of Research Question 2 was to identify coping strategies, the goal of Research Question 3 was to go further to explain relationships and to determine what extent they do or do not exist. Research Question 3 states the following. Do relationships exist between perceived barriers to persistence and coping strategies for nontraditional learners enrolled in a variety of adult undergraduate programs, and if they do exist, to what extent? The design of the study interview included a related question, "Do you think the way(s) you just mentioned as coping with the obstacle was either (a) an effective way to cope, (b) an ineffective way to cope or (c) both effective and ineffective." This question allowed participants to give a response that revealed the nature of the coping strategy. By knowing if the coping strategy employed was effective or ineffective for each participant, it is possible to then show relationships between the coping strategy and the barrier. For example, the majority of participants with Writing Anxiety as a barrier used the strategy "Have Friends/Family/Peers Assist and Review my Assignments before I Turn Them in." Of those that used the strategy, $85.7 \%$ stated that it was an effective strategy to employ. This shows a strong positive relationship between the barrier and an effective coping strategy. In contrast, for the similar barrier Test Anxiety, the most common coping strategy was Worry. This was employed by $31.6 \%$ of interview participants that possess the perceived barrier. Of those, $66.7 \%$ stated that the coping strategy was ineffective. The strong relationship reveals a need to seek effective strategies to deal with Test Anxiety such as Listen to Music before an Exam which was mentioned as effective by all 10.5\% of participants that used this strategy.

Relationships were further revealed in Tables 4 and 5 with the mean score given to each barrier. The mean score details the level of influence each particular barrier has on the participants. Barriers with high scores indicate that there is a stronger relationship between the 
participants and the particular barrier. For example, Test and Writing Anxiety both have very high mean scores whereas Lack of Acceptable Child Care did not. Test and Writing Anxiety were also barriers for a majority of participants while Lack of Acceptable Child Care was the least common of all listed barriers in the survey responses. Further discussion about the research questions related to the results will be detailed in Chapter 4 . 


\section{CHAPTER 4}

\section{Discussion}

The present study investigated perceived persistence barriers and coping strategies for nontraditional learners enrolled in a variety of undergraduate programs. There were three primary components to this study. The components consisted of identifying both internal and external persistence barriers, then identifying coping strategies, and finally determining if relationships exist between the two. Additionally, the study identified demographic participant information in an effort to determine more specific information about the study participants. This was determined to be an essential element of the study. This chapter presents interpretations of the findings yielded from this research. Additionally, considerations are presented for future related research.

The investigation was guided by three research questions. The first part of the study was to determine the demographic participant information and the perceived barriers to persistence for nontradional learners in an effort to answer Research Question 1: What are the perceived barriers to persistence for nontraditional learners enrolled in a variety of adult undergraduate programs? In order to answer this question, a survey was conducted for 100 learners at the Regional Learning Alliance in Cranberry Township, Pennsylvania.

Demographically, the participants were enrolled in primarily 14 programs of study, and $9 \%$ either did not specify a program of study and/or were undeclared majors. The survey participants included 70 females and 30 males. The age range was $45 \%$ ages $25-34,39 \%$ ages $35-48$, and $16 \%$ were age 49 or older. There were 37 ranked as seniors, 23 as juniors, 16 as sophomores, 13 as freshmen, and 11 did not specify or did not know their undergraduate rank. The majority of participants, $59 \%$, did not have any children living at home. Ethnicity was $98 \%$ 
non-Hispanic, and race was $96 \%$ White. While both ethnicity and race were reflective of the community of the campus, it was also not reflective of the American population of nontraditional students as a whole. Therefore, an argument can be made that results may not be generalized to the American population of nontraditional students.

The enrollment status was $48 \%$ full-time, $38 \%$ part-time, and $14 \%$ unspecified. The majority, $66 \%$, have been out of formal education 5-10 years while $33 \%$ were out of formal education for more than 10 years. As expected with the majority of nontraditional students, $79 \%$ were employed. Of that percentage, $60 \%$ reported working at least 37 hours per week. It was found that of the majority of participants that work, $58 \%$, do not have the ability to utilize work time for class preparation or study. The determination that there is a general lack of support from employers is detailed by both this demographic information as well as a reported external barrier. Of the $79 \%$ of participants that work, 39\% (31 participants) reported a lack of employer support as an external barrier that affects them.

Participants reported their primary reasons for education, with personal rewards such as self-esteem being the most common reason. There were $42 \%$ that were seeking a degree in order to gain new employment in a different career field, which is a frequent reason many nontraditional students return to school. Only $5 \%$ reported that their employer required them to continue their education. This could be because participants are in fields that do not require a degree or because they are not required to get a degree in order to keep the position they currently have. It does not indicate that the participant is required to get a degree in order to advance with their current employer. However, $30 \%$ of participants stated a reason for returning to school was to advance at the company they currently employed with. There were $15 \%$ of participants that reported they were seeking a degree in order to receive a raise. 
The majority of participants reported that they do not have roles beyond being a student, parent, spouse, or employee. There were $20 \%$ that reported they participate in volunteer activities within their communities. This information is an indicator that the nontraditional students in this study are managing their time between family, employment, and education primarily. There were $11 \%$ that reported religious activities, however, that could be primarily due to the fact that more than $25 \%$ of the participants were enrolled in two religious-affiliated colleges that often require students to participant in religious activities.

While this researcher examined data collected across the following groups, age range, gender, program of study, relationship status, children living at home, ethnicity, race, institution, years out of formal education, and employment status, there were no obvious recognizable or notable differences or patterns that were specifically studied as part of this particular research. The demographic information could further be analyzed to determine if specific conclusions can be made related to a large combination of variables. Thus, the conclusions detailed in this discussion are presented as representative of all participants in this study. Participants are nontraditional adult learners enrolled in a variety of undergraduate programs of study.

Perceived internal barriers to persistence included common barriers recognized in previous studies as outlined in Chapter 2. The most common perceived internal barrier for the 100 participants in this study was Test Anxiety. Test anxiety was a substantial barrier for $62 \%$ of participants. Following closely was Writing Anxiety with $60 \%$ of participants stating it was a substantial barrier. Most participants that reported test anxiety as a substantial barrier also reported writing anxiety as a substantial barrier. Although this was not true with all participants, it is consistent with related research. While this study recognizes that barriers may be either real, perceived, or both, it is also determined that perception of a barrier makes the barrier real in the 
mind of the participant. While participants may have difficulty with testing and writing, perception of a barrier doesn't necessarily indicate that all participants are performing poorly with either task. It does likely suggest that both testing and writing are the cause of stress for students that perceive these barriers.

The mean score of Test Anxiety for those that reported the barrier as substantial is 3.5. The mean score of Writing Anxiety for those that reported the barriers as substantial is 3.6. The mean for all barriers was taken between those that reported the barrier as a " 2 " or more on a scale of "0" to " 5 " with " 0 " being "Not At All Affected" and "5" being "Strongly Affected." The scoring indicates that for those that find the barrier as applicable to them, the majority find the barrier strongly affects them. The mean score for Writing Anxiety for those that reported the barrier as substantial is 3.6. Similar to Test Anxiety, the score indicates that the perceived barrier strongly affects them.

Equal to each other in number of participants that reported the barriers as substantial, Worry about Ability to Fulfill Family Obligations, Worry about Ability to Fulfill Career Obligations, and Worry about Inability to Learn the Material Taught were reported by $55 \%$ of participants. The mean scores were 3.6, 3.3, and 3.1 respectively. Therefore, the perceived barrier, Worry about Ability to Fulfill Family Obligations, has a rating that infers participants are more strongly affected by this barrier than they are affected by Worry about Ability to Fulfill Career Obligations, and Worry about Inability to Learn the Material Taught. This also indicates that family obligations may be of greater concern to the participants than career obligation or their own ability or capacity to learn. It highlights the importance of family in the lives of the nontraditional learners in this study. 
Fear of Failure was a substantial internal barrier reported by $54 \%$ of participants in the study. The mean score was 3.7 , the highest mean score of any perceived internal or external barrier. This signifies that, of all the internal barriers that were substantial for participants, more rated Fear of Failure as something that strongly affects them than any other barrier. Fear of failure is commonly known to be a prevalent barrier for nontraditional students, and thus, it was not an unexpected outcome. This result spells out the need for efforts by institutions to inspire self-esteem and confidence in students at the very beginning of their program. Because the majority of participants, $60 \%$, were ranked as junior or senior, it is evidence that the barrier Fear of Failure does not necessarily become less of a barrier as a student progresses through his/her program of study. While it may be assumed that fear of failure would be more widespread in freshmen, such was not the case in this study. However, it is not known how many prior credits each participant had before returning to school. Therefore, a participant that reported themselves as a junior ranking may also be a returning student. If the student previously had college credit from 5 or more years previous, those credits could still be applicable to elevate her to such a rank as she begins reentry into college. Finally, past failure as an undergraduate student may very well precipitate a fear of failure in students that have previous college experience.

Lack of motivation was yet another perceived internal barrier that the majority of participants identified. At 53\%, this barrier has a mean score of 3.0 which details that they are affected by the barrier but not strongly or substantially affected. It does stress the importance of faculty, administrators, employers, family, and friends to encourage or inspire these adult learners to progress through their educational journey. What is not easily explained is the relationship between the demographic data which detail that $44 \%$ of participants said the primary reason for going back to school was for Personal Rewards, while at the same time, 53\% of 
participants also lacked motivation. Typically an internal desire and subsequent reward for an accomplishment is not related to a lack of motivation. However, one consideration to possibly explain the result is that motivation at the beginning of a learner's return to school can also quickly disappear as they become discouraged, stressed, or overwhelmed. Therefore, while there may have been sufficient motivation to inspire the learner to enroll and begin a program of study to meet their personal reward of obtaining a degree, that motivation may subsequently fade while the desire to receive the degree remains high.

There were 42 participants that reported the barrier Insufficient Academic Skills and Preparedness affects them. This barrier is typically reported at higher rates for students that have been out of formal educational more than 5 years. The longer a nontraditional student is out of formal education, the more likely a student will rate this barrier as substantial. The mean score of 3.0 (of those that responded with a 2, 3, 4, or 5) signifies that this barrier was listed by a large percentage of participants. However, the barrier did not substantially affect the majority. It is not a surprising result as most of the participants, $87 \%$, have been in their current program of study for more than one semester. Typically, after successfully completing one semester, the percentage of those that feel unprepared academically would be lower than for students enrolled in their first semester upon returning to school.

There were 32\% that reported the barrier Apprehension About Fitting In and 30\% that reported the barrier Apprehension About Meeting Peers And/Or Making Friends. These barriers can be explained further after the subsequent interview with participants. Many of those that reported these barriers stated that they either did not have time to make friends with classmates and/or they initially had such a fear but the fear quickly dissipated after each class began and they met fellow students. Many also stated that they expected to be in a program with much 
younger peers but upon classes starting, soon realized they were surrounded with a majority of nontraditional students which alleviated their apprehension about fitting in and their fear of making friends. Thus, this details the importance of faculty recognizing that students need time very early in the semester to interact with their peers inside and outside of the classroom.

The second stage of the study was to determine the coping strategies used by participants in an effort to answer Research Question 2: What are the coping strategies related to the perceived barriers for nontraditional learners enrolled in a variety of adult undergraduate programs? In order to answer this question, 32 of the 100 survey participants were selected for a subsequent interview. The 32 students represent $10 \%$ of the Regional Learning Alliance undergraduate population. The interview was conducted with questions directly related to how each individual participant coped with each substantial barrier revealed via the survey.

\section{Coping Strategies Related to Internal Barriers}

Participant responses from the interview were coded into categories. While all responses were recorded, only those categories containing two of the same response are considered substantial enough to discuss as coping strategies. Fear of Failure was a substantial internal barrier for 19 of the 32 participants. The coping strategy most commonly employed related to this barrier, for $36.8 \%$ of participants, was Anxiety/Worry. This is a common coping strategy but also one that may not be considered a productive method to cope with this common fear for nontraditional students. However, $28.5 \%$ of participants that utilized this coping strategy stated that this was an effective strategy. It was effective because stress caused them to study longer which in turn helped them to learn and perform better. There were 4 respondents that stated they used the coping strategy Taking One Step At A Time To Success to cope with their fear of failure. This represents $21 \%$ of those that have this barrier. This was also considered an effective 
coping strategy for all 4 participants. Support systems for nontraditional students should consider encouraging these students to focus on being successful at one assignment and one test at a time. Such success may be accomplished by first succeeding at each individual class rather than facing the larger challenge of graduation which may seem like an overwhelming task for returning students. Faculty should be a part of that support system considering another $10.5 \%$ of participants stated that Help from Faculty was another coping strategy used for the barrier Fear of Failure.

Lack of motivation was a barrier for 17 of the 32 participants. Of those 17, there were only a few commonalities among coping strategies revealed. Self-Therapy was a coping strategy for 3 , while 2 reported there was a financial incentive at work that helped them to stay motivated. Two stated they do not have any coping strategy for this barrier. We can conclude that this internal barrier among our participants does not seem to have a common coping strategy.

Insufficient Academic Skills is a barrier that 13 of 32 interview participants listed. The most frequent coping strategy employed was Overcoming Deficiencies As I Progress. This is similar to the coping strategy previously mentioned for Fear of Failure, Take One Step At A Time To Success. The $30.8 \%$ of participants that use this strategy had mixed responses about the effectiveness of this strategy. Of those, $50.0 \%$ stated that it was an effective strategy, and $50.0 \%$ stated it was an ineffective strategy. Among the main coping strategies used to deal with this barrier, $60 \%$ of participants stated that the coping strategies they used were ineffective. Other main coping strategies used were (a) Do The Best With What I Already Know and (b) Struggle To Learn Or Understand. The majority of these students responded that both strategies are ineffective. There were no common effective strategies revealed in this study for the barrier Insufficient Academic Skills. 
Worry About Ability To Fulfill Family Obligations was the most common barrier among the 32 interview participants. It was listed as a barrier for 27 of them and had the most conclusive coping strategy of all internal or external barriers. Spending Less Time With Family was a coping strategy for 13 of the 27 participants. Six of those responses were considered effective, 6 were ineffective and 1 listed the strategy as neither effective nor ineffective. The preponderance of participants described an acceptance of the coping strategy and the barrier. However, many stated that while they accepted the coping strategy Spending Less Time With Family, their families often did not find it to be a reasonable or effective coping mechanism. The next most common coping strategy for this barrier was Attend Less Family Activities. This was listed as a separate coping strategy due to the nature of the description used by participants that utilized this strategy. Most described the coping mechanism as having an absence from their children's sporting, arts activities, and performances along with other special occasions. This was listed as ineffective to most participants.

Dependence Upon Partner To Handle More Family Obligations was a third coping strategy for the barrier Worry About Ability To Fulfill Family Obligations. There was an equal number of effective and ineffective responses to the strategy. This could be primarily due to the willingness of the partner to accept more family responsibilities. Should a partner not become a willing participant, it would be more likely that the participants would respond by stating that the strategy was ineffective. Three participants responded to the barrier by Managing Time In Order To Handle Family Obligations as a coping strategy. That particular coping strategy was effective by all that responded. It details the importance of time management as something students can use as a successful coping strategy. It is an effective and thus productive strategy that can be 
learned. Therefore, administrators and faculty should consider incorporating time management discussion into their curriculums.

Three participants reported using technology to effectively cope with the barrier of Worry About Ability To Fulfill Family Obligations by calling, texting, and emailing their partners and family members when they are unable to be at home or spend time with their family in-person. All stated that the strategy was effective. This strategy is rather new and was not found as a coping strategy in any related previous research.

It is worth mentioning that Ask For Patience And Understanding is a coping strategy used to deal with the same barrier. The majority that used this strategy found it to be effective. It should be noted that many that do not use this strategy may not feel comfortable asking their families for such a request. However, this too could be an effective strategy as part of communicating with their family more about their educational support system. It is another possible inclusion into curriculum that deals with orientation for the returning adult student.

Worry About ability To Fulfill Career Obligations was another common barrier with 20 of 32 participants reporting. There were few common themes for coping strategies used for this barrier. Those that Do Not Allow School To Affect Job as their coping strategy were in the majority of the responses at $20 \%$. Of those, $75 \%$ stated it was an effective strategy to use. There were many descriptions of specific methods used so that school did not affect their jobs. Many allowed their job to dictate their availability of time to attend class sessions. This is likely one stark difference compared to a traditional student which typically allows their education schedule to dictate the time available to work either part-time or full-time. Of all coping strategies for this barrier, those that responded with Miss Class Sessions For Family Obligations, were the highest to rank that particular coping strategy as ineffective at $100 \%$. While adult students may feel an 
obligation from their family to attend functions, they also are individually aware of academic consequences for class absences. No participant had a positive reaction to using this coping strategy with many descriptions of this coping mechanism prefaced with "unfortunately." Getting Little Sleep was also mentioned as a coping strategy. Time management could be a more effective way for dealing with the barrier than Getting Little Sleep.

Apprehension About Fitting In was a barrier for 12 of 32 interview participants. The only common coping strategy revealed was Communicating With Peers And Professors In An Effort To Fit In. For $58 \%$ of the participants, this was the coping strategy used and $100 \%$ stated it was an effective strategy. Only 2 of the 12 participants stated that they were unable to fit in with their peers, but neither participant viewed the coping strategy as ineffective. This may indicate that they either did not care to fit in or it wasn't a priority for them to fit in with their peers.

Worry About Inability To Learn The Material Taught is a barrier that includes many effective coping strategies for 17 participants. Study (more) Until I Learn the Material was an effective coping strategy for all $23.5 \%$ of participants that use this coping strategy. One participant stated that while it was effective, it also required precious time to study and that time was taken away from his family. Confer With Peers To Gain An Understanding is yet another coping strategy related to the importance fellow peers have in the learning process as mentioned earlier. Peers that can communicate to each other about the material taught helps reiterate class discussion and clarify the material. Read The Materials/Books More Than Once To Fully Understand The Material was an additional coping strategy. This is related to students that may not fully grasp the material upon reading for the first time. This could be due to a lack of academic preparedness, worry or anxiety associated with learning the material, or a tendency to allow stress and other factors to take a student's focus rather than the reading material. 
Test and Writing Anxiety were two barriers that received the most responses from participants. The coping strategy for the barrier of Test Anxiety used most by participants was Worry and/or Become Stressed. This coping strategy was only effective for 33\% of participants that stated they used this strategy. Another coping strategy, Forget the Material When Taking a Test, was reported by $30 \%$ of those that have Test Anxiety. All of the participants using (or effected by) this strategy stated that it was ineffective. It is rational to believe that this strategy is ineffective, as forgetting the material during a test helps to lower test scores and the participant's rate of success in the program. It is also rational to understand that anxiety, while a barrier, is also often something that signals a natural physical response. None of the participants had an effective approach to prevent this coping strategy from happening, and thus it appears to be a true symptom of Test Anxiety. One such coping strategy was Listening to Music Before an Exam. This strategy reduced anxiety. We can infer that if anxiety were reduced by the coping strategy Listening To Music, that perhaps the student may forget less of the material when taking an exam. There are other productive methods for test anxiety, while not revealed by participants in this study, these methods could be shared with educators in an effort to teach nontraditional students effective methods for reducing test and writing anxiety.

Another ineffective coping strategy used for the barrier of Test Anxiety was Become Nervous Or Physically Ill. There is an obvious reason why this strategy is ineffective. The relationship between this barrier and the coping strategies used by participants reveals rather ineffective approaches to dealing with the anxiety barrier. Further, it points out the need for effective strategies to be determined and subsequently taught to nontraditional students that have this internal barrier. 
Writing Anxiety included a prevalent coping strategy that was both positive and easily adaptable. Have Friends, Family, And Peers Assist And Review My Assignments Before I Turn Them In was the coping strategy used by $36.8 \%$ of participants that reported the barrier. While this was effective for all $36.8 \%$ of participants, one participant stated it was also ineffective because family had to use their limited free time to assist with this task. Unlike the previous anxiety barrier, this barrier has a predominant effective coping strategy from participants. It highlights the important and positive impact an effective coping strategy can have on a barrier.

\section{Coping Strategies Related to External Barriers}

External barriers have less of an impact on participants in this study than do internal barriers. For internal barriers, 7 of the 10 total given potential perceived barrier topics were reported as a $2-5$ (on a scale of $0-5$ ) by more than $50 \%$ of participants. Whereas for external barriers, of the 9 topics given, only 1 of the barriers was reported as a 2-5 (on a scale of 0-5) by

more than $50 \%$ of participants. That external barrier, Ability To Finance Education, had a mean score of 3.11 for $58 \%$ of the survey participants and by $43.75 \%$ of participants selected for the interview. No external barrier was rated 2-5 (on a scale of 0-5) by a majority of interview participants. However, there were 6 of the 10 internal barrier topics rated as a $2-5$ by a majority (more than 50\%) of interview participants.

The external barrier, Lack Of Spousal/Partner Support, was reported by $24 \%$ of participants in the survey. There were $34.34 \%$ of participants in the interview that reported this external barrier with a mean score of 3.09 on a 2 to 5 scale. Of those that listed the barrier, 2 stated that they did not have a spouse or partner which is why they lacked support and thus reported the barrier. Another 2 participants stated that they Ignore Or Disregard The Lack Of Support From Their Spouse or Partner and that doing so was an ineffective coping strategy. A 
full 33\% of participants that have this barrier stated that the coping strategy they use is to Argue With Their Spouse Or Partner About School (and/or the things they are unable to do because of school). All listed this as an ineffective strategy. There were no coping strategies for this barrier that were listed as effective for more than one participant. It appears as though this particular external barrier is a challenge because no participants in this study employed any effective strategies with their spouse/partner. While the internal barrier, Worry About Ability To Fulfill Family Obligations, included a coping strategy Ask For Patience And Understanding, this external barrier did not include such a coping strategy which would seem like a relevant strategy to employ effectively.

Lack of Other Family Support was reported by 8 of 32 interview participants. This barrier has the highest mean score of all external barriers at 3.13 on the 2-5 scale. Six of eight participants reported using the coping strategy I Rarely Discuss Education With My Family. Of those, 3 stated it was an effective strategy and 3 stated it was in ineffective strategy. The participants further stated that while it helped avoid conflict with family that did not support their education, it also was ineffective because they preferred to have a family support system. There were 2 participants that stated they coped by Accepting That I Am Unable To Rely On My Children Or Parents For Support. These were the only substantial coping strategies stated by interview participants related to the external barrier. It reveals that while many may have family support, those that do not have family support have chosen to either not discuss their educational endeavor with their family and/or to accept that their families do not support their education. Since all participants are currently enrolled, there is no such evidence to support a conclusion that this barrier may support the student dropping out or failing to complete their degree. 
However, it does conclude that the barrier exists for quite a proportion of nontraditional students and thus should not be ignored by administrators and/or faculty.

There were 11 of 32 participants that stated they lack employer support. These participants stated two primary coping strategies to deal with this barrier. The most prevalent coping strategies are (a) Take Out Loans or (b) Pay For Education From Savings. This was only an effective strategy for 1 participant. There is evidence to support that this coping strategy may also be ineffective if presented as a commencement barrier. As a commencement barrier, a student may cope by choosing not to enroll in a program of study and thus not become a student. Surprisingly, no students mentioned changing jobs or asking for a raise as a coping strategy for this barrier. While participants that used this particular coping strategy seemed to understand that their employers did not have tuition reimbursement programs, none mentioned any other strategy other than obtaining an external loan. This is important information for adult education or continuing education departments to know as they can discuss alternatives with potential and current students who may be timid about asking their employer for financial assistance. Clearly, obtaining loans is accepted by students, but it is not considered to be an effective strategy.

A third coping strategy for the barrier Lack Of Employer Support is Making Sure That Classes Do Not Interfere With My Job. All participants that utilize this coping strategy stated that it was an effective strategy. Those that employ this strategy did not mention any related hardships due to using this strategy which details that the strategy is one they are comfortable employing. It also displays a method of prioritizing.

The external barrier that was most recurrent is Ability To Finance My Education. Like the previous barrier, Securing Student Loans, is the most common coping strategy for this barrier. There were 3 of 18 participants that stated they Paid For Tuition By Using Savings as a 
coping strategy. Another 2 coped by Worrying About Repayment Of Loans. While securing loans was a coping strategy, it seems that it became a barrier as well due to the response Worrying About Repayment as a coping strategy. Worry was a common coping strategy throughout both internal and external barriers. It appears to be a common element and one that surely needs attention since it is reported to be ineffective in the vast majority of responses.

The least substantial of all barriers, both internal and external, was Lack Of Acceptable Child Care. Previous studies as noted in the Literature Review, highlighted this as a once major barrier. There were only 4 of 32 interview participants that noted this as a barrier with a mean score of 2.25 on a scale of $2-5$. Of these 4 participants, there weren't any single coping mechanisms used by more than 1 participant. Thus, there are no conclusive coping strategies to report. There is an obvious change related to this barrier from past studies. First, $41 \%$ of participants in the survey reported having children at home under the age of 18. This study did not determine the age at which children do not need full-time childcare. For some parents, this may be when children become teens, for others this varies and thus, this study did not further investigate the demographics associated with those that stated this barrier. The majority of participants, $63 \%$, are married or partnered and thus may have a spouse to assist in the childcare for minor children living at home. While this could be investigated further to gain more information about the decline in childcare as a substantial barrier, what we do know from this study is that it is not a substantial barrier at the Regional Learning Alliance campus as it relates to nontraditional undergraduate students.

There were $37.5 \%$ of participants affected by the barrier Distance To Classroom. A substantial portion, $41.67 \%$ of those participants use the coping strategy Commute A Long Distance Because The Campus Is Still The Closest Campus To My Home. This is an interesting 
coping strategy because there are many online programs that could possibly offer a more feasible option than driving a long distance to campus. There are a large number of adult students that live in rural communities that do not have a college or university in close proximity. However, $25 \%$ of participants that have this barrier stated that online classes do not appeal to them or they fear they would not be successful at online courses. While the presence of online classes has undergone tremendous growth in recent years, such programs do not appeal to a majority of students that currently attend on ground classes at the Regional Learning Alliance. One important point is that students enrolled in total online programs (that may be administered from the Regional Learning Alliance or other campus) were not included in this study. Students enrolled in those programs may have experienced the same barrier, Distance To Classroom, prior to enrollment (as a commencement barrier), and the coping strategy they used was to find a suitable online program of study rather than commute. We do not know that information in this particular study, but it is certainly worth investigation in future study.

Another coping strategy used by participants that stated they have the perceived external barrier Distance To Classroom was Sometimes Arrive Late For Class Due To Class Commute After Work. While this was mentioned by $16.6 \%$ of participants, much of the lateness was due to road condition brought about by weather as well as work requirements that caused them to work late and thus be late for class. This coping strategy was listed equally effective as ineffective for participants. Faculty that display understanding to students that have a need to arrive late would indicate that it could be an effective strategy for the student. However, faculty that do not show understanding for lateness may be a reason the student could find this strategy to be ineffective.

The Design of Program was a perceived external barrier for $25 \%$ of interview participants. The only substantial coping strategy employed was I Am Forced To Extend The 
Time To Complete My Degree Due To Course Offering Conflicts. Participants stated that they often need a set of courses and some within that set were taught on the same day and time and thus prevented them from taking all needed courses the same semester. This in turn extends the time it will take them to graduate. While many institutions at the Regional Learning Alliance have undergraduate programs that are structured as cohorts, others do not have such structure. There are multiple majors at a single institution that require many of the same courses. Thus, it is difficult to schedule all courses so they are not offered the same day and time. With institutions attempting to accommodate working nontraditional students, most courses are scheduled for evening hours primarily Monday, Tuesday, Wednesday, and Thursday. These courses are typically 3 hours in length, taught one evening per week. While that structure is accommodating, some students in a particular program may not be able to find needed courses offered on separate days and times. A possible alternative coping strategy is to take some required courses online or to make special arranged class times with particular departments teaching the specific needed courses.

Related to the above barrier, a similar barrier is Lack Of Feasible Degree Program. This external barrier was shared by 8 of 32 participants. There was just a single coping strategy used by more than 1 of the 8 participants, Chose A Major Because It Fits Around Work Schedule (Even Though it wasn't the Major Preferred). This coping strategy is logical for many of the nontraditional students that attend the Regional Learning Alliance campus because of the proximity to their work or home locations. The campus is located in a region undergoing rapid growth but at the same time, the closest campus to many rural populations within a three-county radius. Therefore, the only feasible choices many adults have that live in one of the rural areas is to (a) either choose a major that fits within their work schedule within a reasonable driving 
distance, or (b) to choose a program offered exclusively online. As stated previously, there are no participants in this study that are enrolled in total online programs.

The last external perceived barrier as listed by 5 of 32 participants is Inability To Meet Program Entrance Requirements. This is a barrier for students that are taking classes but have not yet been officially admitted into their program of choice. While all institutions at the Regional Learning Alliance have home campus locations, most have designed programs at the RLA campus that have leaner entrance requirements. The entrance requirements for most RLA programs are met at the time of enrollment with only a few exceptions. There are two undergraduate nursing programs that have the same entrance requirements as their home campuses, one of which took part in this study. That program requires taking courses and/or improving GPA prior to admittance into the program. The coping strategy most used by those that possess this barrier is to Take Required Developmental Courses Which Extends Graduation Time And Expenses. These requirements are most often dictated by accreditation requirements within each institution. Therefore, this is a barrier that would be difficult for faculty and administrators to change in an effort to ease requirements and thus the barrier for students.

The third research question in this study has been partially addressed by looking further into each coping strategy as Research Question 2 was addressed. Research Question 3 states the following. Do relationships exist between perceived barriers to persistence and coping strategies for nontraditional learners enrolled in a variety of adult undergraduate programs and, if they do exist, to what extent? To further answer this question, there are relationships that became obvious during the course of this investigation.

The extent of relationships existing between perceived persistence barriers and coping strategies is largely measured by the interview response frequencies of coping strategies utilized. 
There were coping strategy commonalities among many different barriers. Worry and anxiety were a common element that students used to cope with both internal and external barriers. The extent of the relationships can be measured by the ineffective rating that was reported by participants that use worry or anxiety as a coping strategy for the various barriers. There was a strong relationship between the ineffective rating of utilizing the coping strategy for virtually all of the applicable barriers. See Tables 4 and 5 for effective versus ineffective responses.

Time management seemed to be an underlying element whose relationship to both barriers and coping strategies were indirectly shown. Time management appears to be both an internal barrier itself, a sub-barrier to other barriers, and a coping mechanism for both internal and external perceived barriers. While participants stated they used elements of time management to cope with Worry About Ability To Fulfill Family Obligations and Worry About Ability To Fulfill Career Obligations as a minimum, they also stated that time management was often a concern because their schedules were full. Thus, the Ability To Effectively Manage Time appears to be a barrier itself. It can be concluded that Time Management is an effective coping strategy for nontraditional students that have the internal barrier of Worry About Ability To Fulfill Family Obligations.

Family understanding and encouragement was a more complex part of the participant interviews. It was clear that students were either proud to have family support or they were discouraged and often upset that their families did not support their educational endeavors. Those that had barriers related to lack of family support displayed more nonverbal discomfort about their coping mechanisms, particularly those that stated they did not choose to share their educational success with family. There were obvious signs of discomfort and stress associated with revealing these coping strategies. Encouragement by family, friends, peers, faculty, and 
employers was an effective coping mechanism for external barriers for all that responded with this or a similar strategy.

Relationships can also be found between the internal barrier Apprehension About Meeting Peers And Making Friends and the internal barrier Worry About Inability To Learn The Material Taught. There was a common coping strategy for both barriers, Conferring Or Communicating With Peers. There were 17.6\% that use that coping strategy when they Worry About Inability To Learn The Material Taught, while $66.67 \%$ use that same coping strategy to deal with Apprehension About Meeting Peers And Making Friends. This result highlights the importance of communicating with peers early and making friends as it becomes a frequent coping strategy to learn the material being taught.

\section{Suggestions for Future Research}

The purpose of this study was to answer the three research questions posed. Throughout the study, additional topics for future investigation arose. One such topic involves research related to the utilization of technology to cope with educational barriers to persistence. It became clear throughout this study that use of technology has become an important and useful tool for nontraditional students. Using mobile telephones to text, email, and call their spouse/partner and family was a useful and effective way to manage time and keep in touch with many social aspects of a student's life. Technology was revealed as a useful tool to cope with barriers related to fulfilling family obligations and test anxiety. Students listened to music with a variety of devices to help prepare them for tests and calm them when stressed or anxious.

Use of social networks related to communicating with peers, faculty, friends, and family is an emerging tool that has taken shape at the end of this study. Students that do not have time to spend in-person with others can now do so with such tools as Facebook and Twitter and are thus 
using these tools as coping strategies to overcome several barriers related to time management, worry, and fear of failure. Investigation of social networking as a tool for the nontraditional student is a topic of interest that educators and administrators may find valuable.

For future study, it would be beneficial to incorporate time management as an internal barrier listed on a similar survey. It was found that the structure and the content of the survey and interview for this investigation was beneficial and appropriate to answer the research questions posed by this investigator. However, because time management was a predominant theme from participants in this investigation, this investigator would recommend incorporating it as a barrier on a future survey to get a clearer picture of the role it plays for nontraditional students.

There were areas of possible expansion in this present investigation which could be further explored. The number of first-generations college students taking part in this study is not known. However, based on the rather high proportion of students having the barrier Lack of Family Support, it could be an indication that there would be a similar proportion of firstgeneration college students enrolled at the Regional Learning Alliance campus. It would further help to explore the gender ratio of first-generation students to compare the Lack of Family Support barrier between genders. If this information is known, it could become a value to administrators that design programming for these adult learners.

Online programs have unique factors that may not have the ability to be measured in the same format as this present investigation. It is important to note that this investigation may not be replicated to research involving students enrolled in online programs without further research related specifically to online student barriers and coping strategies. It is recommended that possible exploration consider these factors before replicating this study. 
The present investigation method was a valuable design to measure both barriers and coping strategies. This investigator recommends consideration of including additional known barriers (specific to the campus or region) to the current survey if replicating. It is important to note that this present investigation does not necessarily have generalization to other similar campuses due to the demographic nature of the student population at the Regional Learning Alliance. Therefore, unique barriers to the institution should always be a consideration in a similar study with adult learners.

There are no recommended adjustments to the structure of the interview but the length of time for each interview may be widened based on the number of given survey barriers. The present investigation offers an in depth view of the relationships between perceived barriers to persistence and coping strategies for adult students than much past research highlighted in Chapter 1. It is finally recommended that future research focus on consideration of the importance of not just exploring barriers or coping strategies singularly but in conjunction with one another.

This current investigation reveals important information about nontraditional students. It would be this investigator's recommendation that future study include the significance of an orientation to the university specifically for nontraditional students. As the research of this study has revealed, there are both effective and ineffective coping strategies employed by nontraditional students. If an orientation program could be developed and taught during a student's first semester enrolled in a new program of study, the class could incorporate many of the effective strategies from this study and teach them as effective tools to overcome barriers. Many nontraditional students find effective coping strategies by trial and error rather than by being taught. This class could prepare students to more effectively deal with both internal and 
external perceived barriers in an effort to learn them quicker in the process of being a student. More research on this idea could be explored.

Finally, this investigation did not explore programs that were online-only. While both the number of programs and the number of students enrolled in online programs have increased dramatically over the last 5 years, the trend may continue. Thus, it would be a recommendation that nontraditional students enrolled in online programs be included in future study to discover if they have similar or dissimilar internal and external barriers. Such study could then find what coping strategies online students use to deal with their unique barriers. Administrators and faculty responsible for online programs would potentially benefit from such study. Having valuable information about barriers nontraditional students face and the coping strategies they use helps to improve curriculum, program design, and other factors which have an impact on persistence, graduation, and learning outcomes. 


\section{References}

Benshoff, J. M., \& Lewis, H. (1992). Nontraditional college students. ERIC Digest. (ERIC Document Reproduction Service No. ED347483). Retrieved January 15, 2008, from ERIC database.

Blodgett-McDeavitt, C. (1997, October). Meaning of participating in technology training: A phenomenology. Paper presented at the meeting of the Midwest Research-to-Practice Conference in Adult, Continuing, and Community Education, Michigan State University, East Lansing, MI. Retreived March 4, 2010, from http://www.iupui.edu/ adulted/mwr2p/prior/blodgett.htm

Bowl, M. (2001). Experiencing the barriers: Non-traditional students entering higher education. Research Papers in Education, 16(2), 141-160.

Carmines, E. G., \& Zeller, R. A. (1991). Reliability and viability assessment. Thousand Oaks, CA: Sage.

Carney-Crompton, S., \& Tan, J. (2002). Support systems, psychological functioning, and academic performance of nontraditional female students. Adult Education Quarterly, 52(2), 140-154. doi:10.1177/0741713602052002005

Chartrand, J. M. (1992). An empirical test of a model of nontraditional student adjustment. Journal of Counseling Psychology, 39(2), 193-202.

Connell, K. (2010). Internal and external barriers to eco-conscious apparel acquisition. International Journal of Consumer Studies, 34(3), 279-286.

Creswell, J. (1998). Qualitative inquiry and research design: Choosing among five traditions. Thousand Oaks, CA: Sage.

Donaldson, J., \& Townsend, B. (2007). Higher education journals' discourse about 
adult undergraduate students. Journal of Higher Education, 78(1), 27-50.

Fairchild, E. E. (2003). Multiple roles of adult learners. New Directions for Student Services, 102, 11-16.

Glaser, B. G., \& Strauss, A. L. (1967). The discovery of grounded theory: Strategies for qualitative research. Chicago: Aldine Publishing Company A phenomenological study of quest-oriented religion. Retrieved October 30, 2010, from http://www.twu.ca/cpsy/Documents/Theses/Matt\%20Thesis.pdf

Graham, M.D. (2001). A phenomenological study of quest-oriented religion. (Thesis, Trinity Western University dissertation, 2001). Retrieved from http://www2.twu.ca/cpsy/Thesis/grahammatthew.pdf

Green, N., Bird, G., \& Piercy, F. (2008). Stressors and coping strategies of African American undergraduates at Virginia Tech, retrieved from Virginia Polytechnic Institute and State University, Multicultural Department Web site: http://www.multicultural.vt.edu /MACSD/proceedings/african,_stress,_coping_proposa.pdf

Hsu, H. \& Tung, H. (2010). What makes you good and happy? Effects of internal and external resources to adaptation and psychological well-being for the disabled elderly in Taiwan'. Aging \& Mental Health, 14(7), 851- 860.

James, K. (2003). How low self-esteem affects adult learners. Adult Learning, 14, 24-27.

Justice, E., \& Dornan, T. (2001). Metacognitive differences between traditional-age and nontraditional-age college students. Adult Education Quarterly, 51(3), 236.

Kazis, R., Callahan, A., Davidson, C., McLeod, A., Bosworth, B., Choitz, V., \& Hoops, J. (2007). Adult learners in higher education: Barriers to success and strategies to improve results. Employment and Training Division Occasional Paper 2007-03. Retrieved November 18, 2010 from http://www.jff.org/Documents/adultlearners.dol.pdf 
Keith, P. M. (2007). Barriers and nontraditional students' use of academic and social services. College Student Journal, 41(1), 123-127.

Kemp, W. C. (2002). Persistence of adult learners in distance education. The American Journal of Distance Education, 16, 65-81.

Knowles, M. (1984). Andragogy in action: Applying modern principles of adult learning. San Francisco: Jossey-Bass.

Leppel, K. (2002). Similarities and differences in the college persistence of men and women. Review of Higher Education, 25(4), 433-50.

Marques, J., \& McCall, C. (2005). The application of interrater reliability as a solidification instrument in a phenomenological study. The Qualitative Report, 10(3), 439-462.

McWhirter, E. H. (1997). Perceived barriers to education and career: Ethnic and gender differences. Journal of Vocational Behavior, 50, 124-140.

Mercer, D. L. (1993). Older coeds: Predicting who will stay this time. Journal of Research and Development in Education, 26(3), 153-161.

Nicolson, C., \& Bess, J. (1997). Stress and anxiety in adult learners in professional and liberal arts schools: An exploration of person-environment fit theory. ASHE Annual Meeting Paper. Retrieved from ERIC database.

Noel, L. (1985). Increasing Student Retention. San Francisco: Jossey-Bass.

Plageman, P., \& Sabina, C. (2010). Perceived family influence on undergraduate adult female students. Journal of Continuing Higher Education, 58(3), 156-166. doi:10.1080/07377363.2010.491768

Price, E. C. (1998). A Comparison of learning styles and coping techniques in 
traditional and nontraditional community college students. Paper presented at the 78th Annual Meeting of the Association of Teacher Educators, Dallas.

Rutter, M., \& Rutter, M. (1992). Developing minds: Challenge and continuity across the life span. New York: Penguin Books.

Sarason, I., \& Ganzer, V. (1962). Effects of test anxiety and reinforcement history on verbal behavior. Journal of Abnormal and Social Psychology, 67(S), 513-519.

Satterlee, A. G. (2002). Conflict resolution strategies for the adult higher education student. Washington, D.C.: United States Army War College.

Schuetze, H., \& Slowey, M. (2002, October). Participation and exclusion: A comparative analysis of non-traditional students and lifelong learners in higher education. Higher Education, 44(3/4), 309-327.

Spellman, N. (2007). Enrollment and retention barriers adult students encounter. The Community College Enterprise, 13(1), 63-79.

Stern, P. C. \& Oskamp, S. (1987). Managing scarce environmental resources. In D. Stokols \& I. Altman (Eds.), Handbook of environmental psychology (pp. 1043-1088). New York: Wiley.

Taniguchi, H., \& Kaufman, G. (2005). Degree completion among nontraditional college students. Social Science Quarterly (Blackwell Publishing Limited), 86(4), 912-927.

Terrell, P. S. (1990). Adapting institutions of higher education to serve adult students' needs. NASPA Journal, 27, 241-247.

Timarong, A., Temaungil, M., \& Sukrad, W. (2002). Adult learning and learners. Honolulu, HI: Pacific Resources for Education and Learning. 
Walberg, H. J. (1997). Families as partners in educational resilience. Phi Delta Kappan, 65, 397400.

Wei, F. (2007). Teaching above and beyond traditional students' needs: A comparison between traditional and nontraditional college students' expectations of classroom communication. Paper presented at the 2007 International Communication Association Annual Meeting, San Francisco.

Yaghmale, S. (2003). Content validity and its estimation. Journal of Medical Education, 3(1), $25-27$. 


\section{Survey for Research Study}

West Virginia University College of Human Resources and Education

Name:

Institution Enrolled:

Program of Study (major):

Email Address: Telephone Number(s):

Are you willing to take part in a follow-up 15 minute interview? $\quad$ Yes $\quad$ No

If yes, best day of week and time for short interview (conducted at the RLA):

1. Undergraduate Rank:

2. Age Range: $\sim 18-24$

3. Relationship Status:

4. Do you have children? $\mathrm{H}$
₹F reshman

25-34

${ }^{\mathrm{M}}$ arried/Partnered

^Y es

No

No

o

$$
\text { ¿So phomore }
$$

Ju nior

49+

¿Single

¿Divorced

W idowed

5. What is your ethnicity? ־Hisp anic or Latino ₹No t Hispanic or Latino

6. What is your race? Please mark one or more races:

Am erican Indian or Alaska Native

If so, how many living at home? ow many under age 18 ?

Nativ e Hawaiian or Other Pacific Islander

Black or African American

Wh ite

7. Enrolled Status: $\quad$ Ful 1-Time (12 credit hours or more) $\quad$ Part -Time

8. How many years were you out of (not enrolled in) formal education before you entered your current institution? $\quad \sim<1 \quad \sim 1-4 \quad \sim 5-10 \quad \sim 10+$

9. Are you employed? $\quad$ Yes No

If yes, how many hours per week do you work? $\quad \sim 0-12 \quad \sim 13-20 \quad \sim 21-36 \sim 37+$

10. If employed, does your employer permit you to use work time to prepare for class, for the time you are in class, or to study? $\quad$ Yes $\quad$ N o

If yes, how many hours per week during work time do you spend for your program of study?
$\sim 1$
$\sim 1-2$
$\sim 2-3$
$3-4$
$\sim 4$

11. What is the primary reason(s) you have decided to continue your education (you may circle more than one choice if applicable)?
A. To seek new employment in a different career field
B. To become promoted with current employer
C. To stay in my current career field but seek a new job with new employer
D. To stay in my current position, but receive a raise
E. Career goals that are not related to financial foals
F. My employer requires that I continue my education 


\section{Appendix 1 \\ G. Personal rewards (such as self esteem) \\ H. Family related reasons \\ I. Other:}

The goal of this study is to examine nontraditional students. The following questions are related to your experience as an undergraduate student:

1. What other current role(s) besides being a student, parent, or spouse do you have (i.e. civic involvement, volunteer, club or association active member etc.)?

2. Internal obstacles are psychological challenges one may face when enrolled in a program of study. The following are typical internal obstacles experienced by nontraditional students after they enroll in a program of study. Please indicate the level to which each affects (or has affected) you in your current role as an adult student. Do not consider any obstacles that you had PRIOR to enrollment that disappeared after your first class.

Please indicate to what extent each obstacle has affected you on a scale of 0 to 5 , with " 0 " being Not Affected At All and "5" being Strongly Affected:

Fear of Failure

Lack of Motivation

Insufficient Academic Skills/Preparedness

Worry About Ability to Fulfill Family Obligations

Worry About Ability to Fulfill Career Obligations

Apprehension About Fitting In

Apprehension About Meeting Peers and/or Making Friends

Worry About Inability to Learn the Material Taught

Test Anxiety

Writing Anxiety

$\begin{array}{llllll}0 & 1 & 2 & 3 & 4 & 5 \\ 0 & 1 & 2 & 3 & 4 & 5 \\ 0 & 1 & 2 & 3 & 4 & 5 \\ 0 & 1 & 2 & 3 & 4 & 5 \\ 0 & 1 & 2 & 3 & 4 & 5 \\ 0 & 1 & 2 & 3 & 4 & 5 \\ 0 & 1 & 2 & 3 & 4 & 5 \\ 0 & 1 & 2 & 3 & 4 & 5 \\ 0 & 1 & 2 & 3 & 4 & 5 \\ 0 & 1 & 2 & 3 & 4 & 5\end{array}$

3. The above list may not have declared all internal obstacles you face as an adult student. Therefore, please list below any other internal obstacles that affect (or have affected) you. Please indicate to what extent each obstacle you list has affected you on a scale of 1 to 5, with "1" being Slightly Affected and "5" being Strongly Affected:
A.
$\begin{array}{lllll}1 & 2 & 3 & 4 & 5\end{array}$
B.

$\begin{array}{lllll}1 & 2 & 3 & 4 & 5\end{array}$
C.

$\begin{array}{lllll}1 & 2 & 3 & 4 & 5\end{array}$

Over $>>>>>>$ 
4. In pursuing your current undergraduate program of study, please select any external obstacles you may have experienced once you began your first class (please circle ALL that apply). External obstacles are challenges presented by your environment that you have faced. Please select all that apply, regardless if they are (or were) real or perceived.

Please indicate to what extent each obstacle has affected you on a scale of 0 to 5, with " 0 " being Not Affected At All and " 5 " being Strongly Affected:

Lack of Spousal/Partner Support

Lack of Other Family Support (i.e. children, parents)

Lack of Employer Support

Ability to Finance My Education

Lack of Acceptable Child Care Options

Distance of Classroom

Design of Program

Inability to Meet Program Entrance Requirements

Lack of Feasible Degree Programs to Apply To

$\begin{array}{llllll}0 & 1 & 2 & 3 & 4 & 5 \\ 0 & 1 & 2 & 3 & 4 & 5 \\ 0 & 1 & 2 & 3 & 4 & 5 \\ 0 & 1 & 2 & 3 & 4 & 5 \\ 0 & 1 & 2 & 3 & 4 & 5 \\ 0 & 1 & 2 & 3 & 4 & 5 \\ 0 & 1 & 2 & 3 & 4 & 5 \\ 0 & 1 & 2 & 3 & 4 & 5 \\ 0 & 1 & 2 & 3 & 4 & 5\end{array}$

5. The above list may not have declared all external obstacles you face as an adult student. Therefore, please list below any other external obstacles that affect (or have affected) you. Please indicate to what extent each obstacle you list has affected you on a scale of 1 to 5, with "1" being Slightly Affected and "5" being Strongly Affected:
A.
$\begin{array}{lllll}1 & 2 & 3 & 4 & 5\end{array}$
B.

$\begin{array}{lllll}1 & 2 & 3 & 4 & 5\end{array}$
C.

$\begin{array}{lllll}1 & 2 & 3 & 4 & 5\end{array}$


Appendix 2

\section{Interview for Research Study}

West Virginia University College of Human Resources and Education

Name:

Institution Enrolled:

Program of Study (major):

Email Address: Telephone Number:

\section{Instructions for conduct of the interview}

7. The interview should take no longer than 15 minutes

8. Please ask the questions in the order noted below

9. Explain to participant that the interview will be used to satisfy dissertation requirements as well to understand more about the Regional Learning Alliance adult student population

10. Explain that their responses will remain completely anonymous

11. Explain that the interview will be recorded for transcription purposes and that after transcription, the interview will be destroyed

12. Set the recorder and the time and begin

1. In the survey you completed, you mentioned the following as obstacles you experienced after enrolling in your program of study:

Read the list of all obstacles (barriers) that the individual listed on the survey.

Are there any other barriers you have thought about that I did not mention? (if participant states any others, add them to their list of barriers).

2. I'm going to ask you to follow up on each of your obstacles that I just mentioned.

For the first obstacle of XXXX, please describe how you coped (or are coping) with that obstacle.

(Repeat each obstacle the participant mentioned in the survey, one at time, back to the participant and then ask the question after each barrier)

3. (After each obstacle response for \#2, please ask the student) Do you think the way(s) you just mentioned as coping with the obstacle was either a) an effective way to cope, b) an ineffective way to cope or c) both effective and ineffective. If the participant responds with "c", please ask them to explain.

4. Anything else you would like to add about the obstacle and the way you coped with it? 